\title{
DESENVOLVIMENTO DO CONHECIMENTO PEDAGÓGICO DO CONTEÚDO (PCK) DE UMA LICENCIANDA EM QUÍMICA NO ESTÁGIO SUPERVISIONADO
}

\author{
VIVIANE ARRIGO \\ ORCID: https://orcid.org/0000-0002-0683-8387 \\ ÁLVARO LORENCINI JÚNIOR ${ }^{2}$ \\ ORCID: https://orcid.org/0000-0001-9365-2312 \\ FABIELE CRISTIANE DIAS BROIETTI ${ }^{3}$ \\ ORCID: https://orcid.org/0000-0002-0638-3036 \\ LEILA INÊS FOLLMANN FREIRE ${ }^{4}$ \\ ORCID: https://orcid.org/0000-0002-6679-411X
}

\begin{abstract}
RESUMO: O presente estudo tem como foco de investigação o desenvolvimento do conhecimento pedagógico do conteúdo (PCK) de uma licencianda em Química, no contexto do Estágio Supervisionado. Nosso objetivo residiu em identificar e caracterizar os conhecimentos desenvolvidos pela licencianda sob a perspectiva do PCK ao planejar e implementar atividades de ensino no Estágio de Regência. Durante esse processo, as discussões com a licencianda foram gravadas em áudio, transcritas e analisadas com base na análise textual discursiva. Em seguida, interpretamos as categorias emergentes com base no modelo de Shulman sobre o PCK e em outros modelos que dele se desdobraram. Os resultados encontrados revelam que, durante o planejamento, o PCK foi mobilizado tendo como ponto de partida o conhecimento do conteúdo, que sustentou a mobilização de outros conhecimentos da base, como o pedagógico geral e o de contexto, de acordo com os seus propósitos de ensino, as características das estratégias de ensino adotadas e as situações de ensino já vivenciadas com os alunos. Após as aulas serem ministradas, percebemos que ocorreu a ampliação do PCK da licencianda por meio de um processo reflexivo que deu origem a cinco categorias: Aprendizagem, Participação, Planejamento, Interação professor-aluno e Mediação Pedagógica do Conteúdo, que, entendemos, representam aspectos que já faziam parte do seu PCK e que se ampliaram por meio da validação da própria prática. Defendemos, portanto, que o desenvolvimento do PCK, neste caso, ocorreu de forma intermediária entre o modelo integrativo e o transformativo proposto por Gess-Newsome (1999).
\end{abstract}

Palavras-chave: ensino de Química, conhecimento pedagógico do conteúdo, formação inicial de professores, Estágio Supervisionado.

\footnotetext{
${ }^{1}$ Universidade Estadual de Londrina (UEL). Londrina, PR, Brasil. < viviane_arrigo@hotmail.com>

2 Universidade Estadual de Londrina (UEL). Londrina, PR, Brasil.<alvarojr@uel.br>

${ }^{3}$ Universidade Estadual de Londrina (UEL). Londrina, PR, Brasil.<fabieledias@uel.br>

${ }^{4}$ Universidade Estadual de Ponta Grossa (UEPG). Ponta Grossa, PR, Brasil. <leilaiffreire@gmail.com> Educação em Revista|Belo Horizonte|v.38|e33826|2022
} 


\title{
DEVELOPMENT OF THE PEDAGOGICAL CONTENT KNOWLEDGE (PCK) OF A PRE-SERVICE CHEMISTRY TEACHER IN THE SUPERVISED INTERNSHIP
}

\begin{abstract}
The present study focuses on the development of the pedagogical content knowledge (PCK) of a pre-service Chemistry teacher, in the context of the Supervised Internship. Our objective was to identify and characterize the knowledge developed by the pre-service teacher from the perspective of PCK when planning and implementing teaching activities in the Teaching Internship. During this process, the discussions with the pre-service teacher were audio recorded, transcribed and analyzed based on discursive textual analysis. Then, we interpreted the emerging categories based on Shulman's model of PCK and on other models that unfolded from it. The results found reveal that during the planning, the PCK was mobilized having as its starting point the content knowledge, which supported the mobilization of other knowledge of the base, such as the general pedagogical knowledge and the context knowledge, according to the teaching purposes, the characteristics of the adopted teaching strategies and the teaching situations already experienced with the students. After the classes were taught, we realized that there was an expansion of the pre-service chemistry teacher's PCK through a reflexive process that gave rise to five categories: Learning, Participation, Planning, Teacher-student interaction and Pedagogical Content Mediation, which we understand to represent aspects that were already part of the PCK and which were expanded through the validation of the pre-service teacher's own practice. We argue, therefore, that the development of the PCK, in this case, occurred in an intermediate way between the integrative and the transformative model proposed by Gess-Newsome (1999).
\end{abstract}

Keywords: Chemistry teaching, pedagogical content knowledge, pre-service teacher education, Supervised Internship.

\section{DESARROLLO DEL CONOCIMIENTO PEDAGÓGICO DE CONTENIDOS (PCK) DE UN FUTURO PROFESOR DE QUÍMICA EM LA PRÁCTICA DOCENTE SUPERVISADA}

RESÚMEN: El presente estudio se centra en el desarrollo del conocimiento pedagógico del contenido (PCK) de un estudiante en Química, en el contexto de la Práctica Supervisada. Nuestro objetivo fue identificar y caracterizar los conocimientos desarrollados desde la perspectiva del PCK a la hora de planificar e implementar actividades docentes. Durante este proceso, las discusiones con el alumno fueron grabadas en audio, transcritas y analizadas a partir del análisis textual discursiva. Luego, interpretamos las categorías emergentes basándonos en el modelo de Shulman en el PCK y en otros modelos que se desarrollaron a partir de él. Los resultados encontrados revelan que durante la planificación, el PCK se movilizó teniendo como punto de partida el conocimiento del contenido, que apoyó la movilización de otros conocimientos de base, como el pedagógico general y el contextual, de acuerdo con sus fines didácticos, las características de las estrategias de enseñanza adoptadas y las situaciones de enseñanza ya vividas con los estudiantes. Luego de las clases, notamos que el PCK del futuro docente se expandió a través de un proceso reflexivo que dio lugar a cinco categorías: Aprendizaje, Participación, Planificación, Interacción docente-alumno y Mediación de Contenidos Pedagógicos, que entendemos por representar aspectos que ya hicieron parte de su PCK y que se han ampliado a través de la validación de su propia práctica. Argumentamos, por tanto, que el desarrollo del PCK, en este caso, se produjo de forma intermedia entre el modelo integrador y el transformador propuesto por GessNewsome (1999).

Palabras clave: enseñanza de la Química, conocimiento pedagógico de contenidos, formación inicial del profesorado, Prácticas Supervisadas. 


\section{INTRODUÇÃO}

Carvalho e Gil-Pérez (2011) apontam que há a necessidade de se repensar a formação docente a partir da análise de como as práticas de ensino vêm sendo desenvolvidas ao longo dos cursos de formação inicial, buscando-se a superação dos currículos que pressupõem um ensino pautado no modelo da racionalidade técnica, caracterizados pela falta de integração disciplinar, levando à preparação do professor como um técnico que não apresenta formação reflexiva para lidar com a complexidade do contexto escolar.

Nesse sentido, Diniz-Pereira (2019) afirma que uma das dicotomias a serem superadas na formação de professores, em busca do desenvolvimento profissional docente, é a separação entre a formação e o trabalho docente. O desenvolvimento profissional docente é definido por García (2009) como um processo individual e coletivo que ocorre a longo prazo à medida que se integram diferentes tipos de oportunidades e experiências e que a escola se concretiza no ambiente de trabalho. O autor ainda o enquadra

[...] na procura da identidade profissional, na forma como os professores se definem a si mesmos e aos outros. É uma construção do eu profissional, que evolui ao longo das suas carreiras. Que pode ser influenciado pela escola, pelas reformas e contextos políticos, e que integra o compromisso pessoal, a disponibilidade para aprender a ensinar, as crenças, os valores, o conhecimento sobre as matérias que ensinam e como as ensinam, as experiências passadas, assim como a própria vulnerabilidade profissional. As identidades profissionais configuram um complexo emaranhado de histórias, conhecimentos, processos e rituais (GARCÍA, 2009, p. 7).

Portanto, falar de indissociabilidade entre formação e trabalho docente na formação inicial de professores requer pensar na forma como os cursos de licenciatura estão organizados e quais as ações formativas têm sido realizadas para promover a articulação teoria e prática ao longo do processo de formação. Para isso, como apontam Broietti e Stanzani (2016), há a necessidade de uma formação embasada na integração de distintos conhecimentos, mediante a articulação entre teoria e prática, de modo a preparar os futuros professores com qualidade científica e princípios didáticos para o exercício da docência.

De acordo com a Resolução CNE/CP 02/2015, ao longo do processo de formação do profissional do magistério da educação básica, deverá ser garantida "efetiva e concomitante relação entre teoria e prática, ambas fornecendo elementos básicos para o desenvolvimento dos conhecimentos e habilidades necessários à docência" (BRASIL, 2015, p. 30-31). Para isso, entendemos que é preciso orientar a formação de professores com base em uma epistemologia oposta à racionalidade técnica, tomando como perspectiva de formação uma epistemologia embasada na prática, que visa à formação do professor como um profissional reflexivo, conforme discute Schön $(1992,2000)$. Segundo o autor, o pensamento reflexivo pode levar o profissional à permanente descoberta de formas de desempenho de qualidade por meio da investigação e reflexão da sua própria prática - ideia que também é compartilhada por Silva e Schnetzler (2008), que afirmam que a reflexão sobre a própria prática possibilita ao futuro professor de Química se converter em um investigador na sala de aula.

Neste sentido, entendemos que o Estágio Supervisionado se apresenta como um rico espaço de construção de conhecimentos para a docência por meio da articulação entre a teoria e a prática e a reflexão acerca das situações de ensino vivenciadas nas escolas-campo de estágio, possibilitando o desenvolvimento de habilidades de planejar, implementar, avaliar, refletir e construir novos entendimentos acerca da docência. É nesse caminho que guiamos a construção deste trabalho, o qual traz alguns resultados de uma investigação de Doutorado que apresenta como cenário investigativo a formação inicial de professores de Química, no contexto do Estágio Supervisionado. 
Trata-se de uma investigação que teve como foco principal analisar o desenvolvimento do conhecimento pedagógico do conteúdo de uma licencianda em Química durante o planejamento e a implementação de atividades de ensino no Estágio de Regência, tendo em vista o seu desenvolvimento profissional docente. Para isso, tomamos como apoio as teorias de Shulman $(1986,1987)$ sobre o desenvolvimento do conhecimento pedagógico do conteúdo (PCK, em inglês Pedagogical Content Knowledge) e da base de conhecimentos docentes. Logo, objetivamos identificar e caracterizar os conhecimentos desenvolvidos pela licencianda sob a perspectiva do PCK ao planejar e implementar atividades de ensino no estágio de regência.

\section{APORTE TEÓRICO}

\section{O conhecimento pedagógico do conteúdo (PCK)}

Shulman (1986) ressalta que é preciso valorizar o conhecimento do conteúdo específico dentre os conhecimentos dos professores e que esse item está no centro da sua profissionalização. Compreendemos que a especificidade de cada disciplina requer do professor astúcia, aptidões e habilidades e um arsenal de conhecimentos para o desenvolvimento de uma prática docente de qualidade e que possibilite aos alunos a compreensão do conteúdo que está sendo ensinado. Nesse sentido, Shulman (1986) explica que o conhecimento do conteúdo específico é composto por três categorias: Conhecimento do Conteúdo, Conhecimento Curricular e Conhecimento Pedagógico do Conteúdo. O conhecimento do conteúdo é definido pelo autor como "a quantidade e a organização do conhecimento específico na mente do professor" (SHULMAN, 1986, p. 9, tradução nossa).

$\mathrm{Na}$ leitura de Goes (2014) sobre a definição apresentada por Shulman, é preciso estar claro para o professor porque um dado conteúdo é central para um tema enquanto outro conteúdo pode ser periférico para o mesmo tema. Nesse sentido, interpretamos que um conteúdo pode englobar vários conceitos que podem ser classificados como centrais ou periféricos, de acordo com as intenções do professor e dos seus objetivos para com o ensino de cada conteúdo. Entendemos, portanto, que Shulman (1986) se refere ao conhecimento do conteúdo tanto em termos de quantidade quanto de organização, pelo fato de esse tipo de conhecimento não se referir apenas ao acúmulo de um conjunto de conceitos na mente do professor, que deve ser transmitido e acumulado na mente dos alunos, mas pressupõe também um conhecimento aprofundado da conexão existente entre esses conceitos.

Por conseguinte, o conhecimento curricular se refere ao conhecimento dos currículos das disciplinas, sendo o currículo definido pelo autor como "uma gama completa de programas destinados ao ensino de assuntos e tópicos específicos em um determinado nível" (SHULMAN, 1986, p. 10, tradução nossa). Assim, nosso entendimento sobre esse tipo de conhecimento faz referência aos conteúdos a serem trabalhados em cada nível de ensino, assim como às estratégias metodológicas e às formas de avaliação empregadas. A terceira categoria refere-se ao Conhecimento Pedagógico do Conteúdo, que, segundo o autor,

[...] vai além do conhecimento do assunto em si, chegando à dimensão do conhecimento do assunto para o ensino. Ainda falo [Shulman] aqui de conhecimento de conteúdo, mas da forma particular de conhecimento de conteúdo que incorpora os aspectos do conteúdo mais pertinentes à sua capacidade de ensino ${ }^{7}$ (SHULMAN, 1986, p. 9, tradução e inserção nossas).

Compreendemos que esse tipo de conhecimento se refere tanto à forma como o professor organiza, relaciona e delimita os tópicos do conteúdo a serem abordados, quanto à maneira como ele é ensinado para que os alunos possam compreendê-lo. Nesse sentido, Shulman (1986) discute que o PCK abrange os entendimentos das mais variadas formas de representação dos tópicos de um conteúdo, as

\footnotetext{
5 Traduzido livremente a partir de: “[...] the amount and organization of knowledge per se in the mind of the teacher".

${ }^{6}$ Traduzido livremente a partir de: "[...] a full range of programs designed for the teaching of particular subjects and topics at a given level $[. .]$.$" .$

7 Traduzido livremente a partir de: "[...] which goes beyond knowledge of subject matter per se to the dimension of subject matter knowledge for teaching. I still speak of content knowledge here, but of the particular form of content knowledge that embodies the aspects of content most germane to its teachability". 
analogias, as ilustrações, os exemplos e as explicações, ou seja, as formas de representar e formular o conteúdo que o tornam compreensível para os outros, assim como o conhecimento da compreensão dos estudantes, ou seja, as concepções que alunos de diferentes idades e origens trazem consigo que influenciam na aprendizagem dos conteúdos.

$\mathrm{Na}$ leitura de Fernandez (2015), Shulman apresenta o PCK constituído por dois componentes: "conhecimentos de representações do conteúdo específico e das estratégias instrucionais, por um lado, e o entendimento das dificuldades de aprendizagem e as concepções dos estudantes de um conteúdo, por outro" (FERNANDEZ, 2015, p. 506). Em nosso entendimento, o primeiro revela-se por meio de conhecimentos acerca da forma como o conteúdo pode ser organizado, explanado e discutido com os alunos durante as aulas, assim como o conhecimento de estratégias e metodologias de ensino que favoreçam o seu aprendizado e conduzam os alunos a elaborações conceituais. Já o segundo, interpretamos revelar-se pelos entendimentos do professor acerca da aprendizagem dos alunos, mais especificamente à forma como eles se relacionam com os conteúdos, demonstrando afinidade e/ou dificuldade na compreensão dos conceitos trabalhados.

Posto isso, em 1987 o autor propõe uma Base de Conhecimentos de professores para o ensino, constituída por sete conhecimentos, como vemos a seguir:

\footnotetext{
- Conhecimento do Conteúdo;

- Conhecimento Pedagógico Geral, com referência especial a amplos princípios e estratégias de gestão e organização da sala de aula que parecem transcender o assunto;

- Conhecimento do Currículo, com compreensão particular dos materiais e programas que servem como "ferramentas do ofício" para os professores;

- Conhecimento Pedagógico do Conteúdo (PCK), aquele amálgama especial entre conteúdo e pedagogia que é exclusivamente do domínio dos professores, sua própria forma de entendimento profissional;

- Conhecimento dos alunos e suas características;

- Conhecimento dos contextos educacionais, desde o funcionamento do grupo ou da sala de aula, a administração dos distritos escolares, até a caracterização das comunidades e culturas;

- Conhecimento dos fins, propósitos e valores educacionais e suas bases filosóficas e históricas ${ }^{8}$ (SHULMAN, 1987, p. 8, tradução nossa).
}

De acordo com a teoria de Shulman, o PCK destaca-se como um conhecimento exclusivo de professores constituído pela combinação de conteúdos específicos e pedagógicos, que está no centro dos conhecimentos de professores; assim, é necessário ao professor dominar e transformar os conhecimentos da base em PCK. Logo, o PCK representa um conhecimento construído a partir dos outros conhecimentos da base, alicerçado em experiências práticas de ensino, de um diálogo com a própria prática (SHULMAN, 1987; FERNANDEZ, 2015).

Após a proposta de Shulman, outros modelos de PCK foram propostos, sendo Grossman (1990) quem sistematizou pela primeira vez os conhecimentos da base e o PCK, como vemos na Figura 1.

\footnotetext{
8 Traduzido livremente a partir de: “- content knowledge; - general pedagogical knowledge, with special reference to those broad principales and strategies of classroom management and organization that appear to transcend subject matter; curriculum knowledge, with particular grasp of the materials and programs that serve as "tools of the trade" for teachers; pedagogical content knowledge, that special amalgam of content and pedagogy that is uniquely the province of teachers, their own special form of professional understanding; - knowledge of learners and their characteristics; - knowledge of educational contexts, ranging from the workings of the group or classroom, the governance and financing of school districts, to the character of communities and cultures; - knowledge of educational ends, purposes, and values, and their philosophical and historical grounds". 
Figura 1 - Modelo de conhecimento de professores

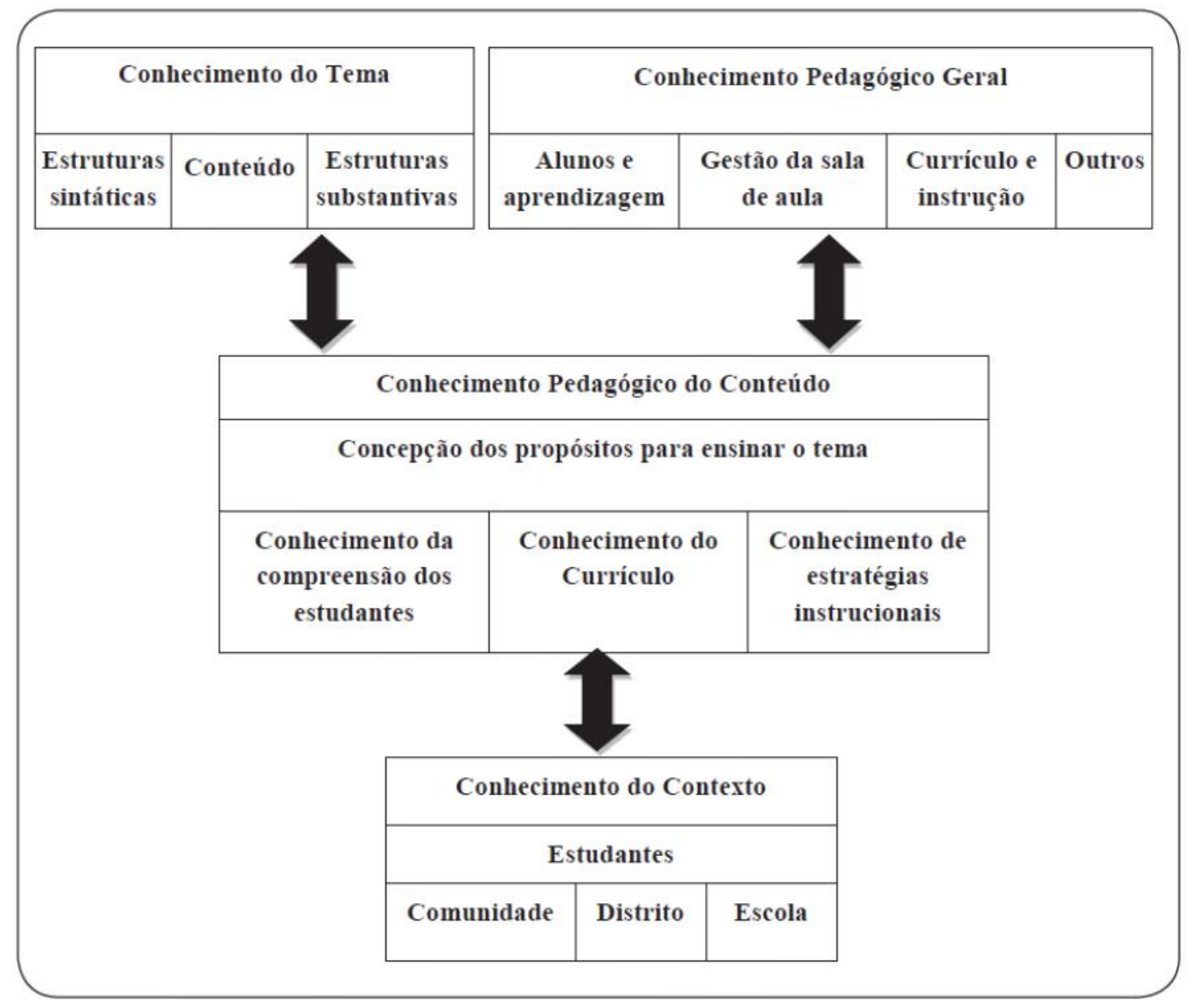

Fonte: Grossman (1990, p. 5, tradução nossa).

Com base nas sete categorias propostas por Shulman, Grossman (1990) alocou quatro áreas gerais do conhecimento do professor como os pilares do conhecimento para o ensino: conhecimento pedagógico geral, conhecimento do tema, conhecimento pedagógico do conteúdo e conhecimento do contexto. O conhecimento pedagógico geral inclui um corpo de conhecimentos, crenças e habilidades gerais relacionados ao ensino. A esse corpo de conhecimentos ela inclui os que estão relacionados aos alunos e à aprendizagem, à gestão e ao gerenciamento de sala de aula, aos princípios gerais de instrução e aos objetivos e propósitos da educação.

O conhecimento do conteúdo "refere-se ao conhecimento dos principais fatos e conceitos dentro de um campo (área de conhecimento) e às relações entre eles"” (GROSSMAN, 1990, p. 6, tradução nossa). Além disso, a autora também destaca as estruturas substantivas e sintáticas que englobam esse tipo de conhecimento, sendo as substantivas aquelas que se referem aos paradigmas e às questões de investigação que afetam a forma como um campo de conhecimentos é construído e organizado. As estruturas sintáticas incluem uma compreensão do conjunto de provas e evidências dentro da disciplina e como os argumentos e explicações provenientes de investigações são avaliadas pelos membros da disciplina (GROSSMAN, 1990).

O conhecimento do contexto inclui o conhecimento dos distritos e do ambiente escolar em que os professores trabalham, das oportunidades, expectativas e restrições impostas por tais ambientes, da "cultura", diretrizes departamentais e de outros fatores contextuais da escola que afetam a atividade docente. Essas esferas incluem o conhecimento dos alunos, das comunidades específicas às quais pertencem, das famílias, suas experiências, pontos fortes e fracos e interesses (GROSSMAN, 1990).

Grossman (1990) explica que o PCK está composto por quatro componentes: os propósitos (conhecimentos e crenças) acerca do ensino de temas específicos em diferentes níveis de ensino; o conhecimento da compreensão e as concepções dos estudantes de diferentes tópicos de um conteúdo;

9 Traduzido livremente a partir de: "Knowledge of content refers to knowledge of the major facts and concepts within a field and the relationships among them". 
o conhecimento do currículo; e o conhecimento das estratégias instrucionais e representações do conteúdo. Portanto, a autora coloca o PCK como um conhecimento central entre o conhecimento pedagógico geral, o conhecimento do tema e o conhecimento do contexto, subordinado aos quatro componentes apresentados. Isso reforça a proposta de Shulman (1986) de que o PCK se constrói e se desenvolve a partir da transformação dos conhecimentos da base; portanto, seu desenvolvimento influencia tais conhecimentos e é por eles influenciado (GROSSMAN, 1990).

Alicerçada nas propostas de Shulman e Grossman e na tentativa de compreender a natureza do desenvolvimento do conhecimento dos professores, Gess-Newsome (1999) propôs dois modelos diferentes de desenvolvimento do PCK, que representam o extremo de um contínuo: o Modelo Integrativo e o Modelo Transformativo, representados pela Figura 2.

Figura 2 - Modelos de desenvolvimento do conhecimento do professor
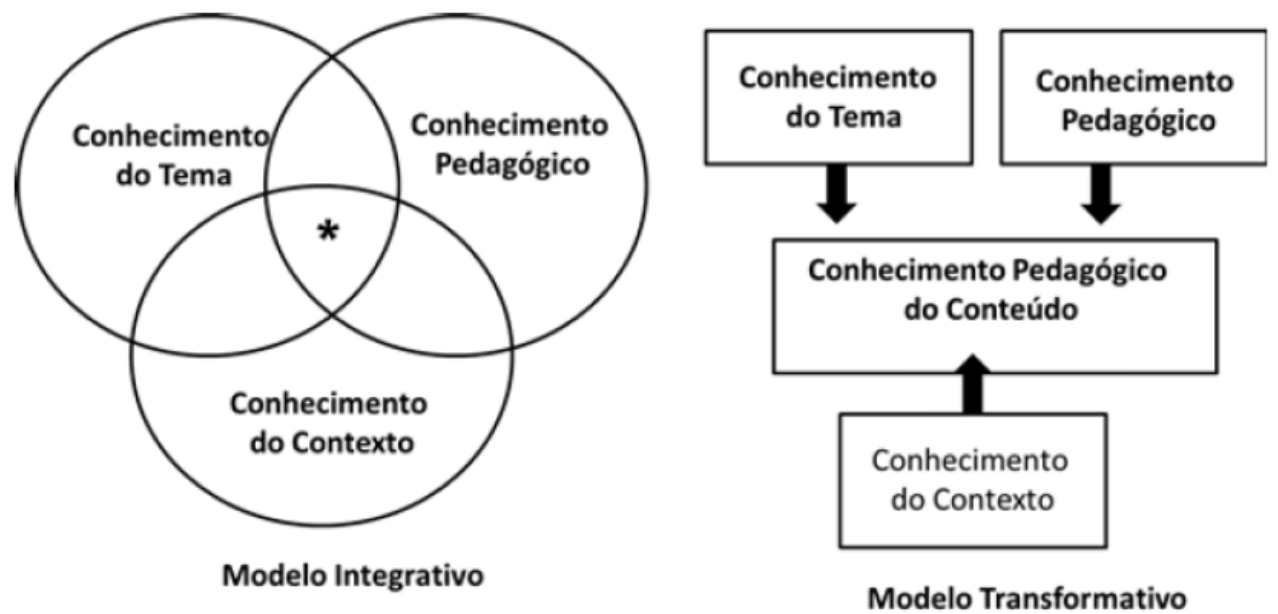

* conhecimento necessário para o ensino em sala de aula (conhecimento pedagógico do conteúdo)

Fonte: Gess-Newsome (1999, p. 12, tradução nossa).

Em um extremo, o PCK não existe como um domínio de conhecimento, e o conhecimento do professor pode ser mais facilmente explicado pela intersecção de três construtos: tema (conteúdo específico), conhecimento pedagógico e conhecimento do contexto. Nesse caso, o ato de ensino ocorre pela integração entre esses três domínios, ou seja, depende da apresentação do conteúdo aos alunos em algum contexto, utilizando-se uma forma apropriada de ensino. Esse é o modelo denominado integrativo.

No outro extremo, o PCK é a síntese de todos os conhecimentos necessários para ser um professor. Nessa situação, o desenvolvimento do PCK dá-se pela transformação dos três domínios de conhecimento em uma forma única, um conhecimento base necessário à prática de ensino do professor. Logo, o PCK é entendido como o conhecimento base para o ensino. Esse modelo é chamado de transformativo. Nesse modelo, o ponto principal não é o desenvolvimento dos domínios de conhecimento, mas como eles se transformam em PCK na prática de ensino (GESS-NEWSOME, 1999).

Para explicar as sutis distinções entre os dois modelos, a autora utiliza uma analogia da Química, comparando-os aos processos de formação de uma mistura (água com areia) e de um composto (amônia). Quando dois materiais são misturados, eles podem formar uma mistura ou um composto; no entanto, o que diferencia um processo do outro é o fato de que, na mistura, os materiais originais permanecem quimicamente distintos, podendo ser recuperados por algum processo físico.

De acordo com Gess-Newsome (1999), o Modelo Integrativo é análogo a uma mistura como água e areia, e o Modelo Transformativo, análogo à reação de formação da amônia a partir dos gases hidrogênio $\left(\mathrm{H}_{2}\right)$ e nitrogênio $\left(\mathrm{N}_{2}\right)$. Ambos estão presentes nos processos formativos docentes. Independente do modelo presente, é importante que os conhecimentos basilares sejam relacionados e que se reconheça a importância dos domínios de conhecimento para o desenvolvimento do PCK, assim 
como das experiências oriundas das práticas de ensino, o que envolve reflexão crítica, tomada de decisões, reconhecimento dos alunos e do contexto escolar (GESS-NEWSOME, 1999).

Fernandez (2015) apresenta um apanhado geral de outros modelos de PCK retratados na literatura, elaborados a partir da proposta de Shulman. Os modelos são: Modelo de Carlsen (1999); de Morine-Dershimer e Kent (1999); de Rollnick et al. (2008); de Magnusson, Krajcik e Borko (1999); de Park e Oliver (2008); de Abbel (2008); e o mais recente deles, o Modelo da Cúpula do PCK, proposto em 2012, em uma conferência da qual participaram 30 grupos de pesquisadores em Ensino de Ciências (Ensino de Física, Química e Biologia) que trabalham com PCK (FERNANDEZ, 2015). Em Hume, Cooper e Borowski (2019), podemos encontrar uma perspectiva atualizada a respeito do avanço das pesquisas sobre o PCK na formação de professores de Ciências. Na obra é apresentado o Modelo Consensual Refinado do PCK, proposto em 2016 com base no modelo do PCK da Cúpula, com a finalidade de investigar a natureza do PCK no ensino de Ciências em uma variedade de contextos de educação científica.

Assim, diante das inúmeras possibilidades para analisar o PCK de professores de Ciências em formação, ressaltamos que, nesta investigação, tomamos como base teórica a proposta inicial de Shulman e os primeiros modelos que dela se desdobraram (GROSSMAN, 1990; GESS-NEWSOME, 1999), conforme apresentados na fundamentação teórica deste trabalho.

\section{OS PROCEDIMENTOS METODOLÓGICOS}

\section{O Contexto da investigação e a coleta dos dados}

Efetuamos a presente investigação durante a realização das atividades de Estágio Supervisionado por licenciandos em Química, em específico o Estágio de Regência. Tais atividades são parte de uma das disciplinas do curso de Licenciatura em Química de uma universidade pública do estado do Paraná, que acontece sob orientação do(a) professor(a)-formador(a), aqui denominada também de pesquisadora-formadora, por se tratar de uma das autoras deste trabalho. Trata-se de uma disciplina anual da $4^{\text {a }}$ série do curso de Química - Habilitação Licenciatura -, que se cumpre com atividades realizadas tanto na universidade quanto nas escolas da região, com duração de 144 horas práticas.

Nesse Estágio de Regência são elaboradas e desenvolvidas aulas experimentais (propostas na forma de atividade experimental - AE -, embasadas nos princípios da experimentação investigativa) e aulas teóricas (que resultam em uma Sequência Didática - SD -, apoiada na abordagem dos Três Momentos Pedagógicos - 3MP). Os 3MP, propostos por Delizoicov, Angotti e Pernambuco (2011), referem-se a uma abordagem que tem suas bases teóricas na pedagogia de Paulo Freire, e por isso seu encaminhamento se dá a partir de um tema gerador que deve ser definido de acordo com o contexto dos alunos, da escola e da comunidade à qual pertencem. Os autores entendem que um ensino baseado em temas associados ao contexto social, econômico e cultural dos alunos pode contribuir para despertar o seu interesse em buscar novos conhecimentos, além de ampliar os já existentes. Assim, a referida abordagem consiste em um encaminhamento didático que se dá em três etapas: problematização inicial (PI), organização do conhecimento (OC) e aplicação do conhecimento (AC).

Na problematização inicial (PI), deve ser oportunizada aos alunos a exposição de suas ideias prévias acerca do tema em estudo; por isso, há a necessidade de se apresentar um problema a ser solucionado, o qual, além de estar relacionado a situações reais do contexto dos alunos, deve promover a ligação com o conteúdo específico. Ocorre que eles, provavelmente, não dispõem dos conhecimentos necessários para interpretar tal problema de forma totalmente correta, ou seja, podem apresentar noções acerca do tema em discussão advindas da sua aprendizagem anterior, dentro ou fora da escola, que precisam ser reconstruídas para a total compreensão e solução do problema (DELIZOICOV; ANGOTTI; PERNAMBUCO, 2011). Logo, é preciso que os alunos construam novos conhecimentos, o que deve ocorrer no segundo momento pedagógico, a organização do conhecimento (OC).

Segundo os autores, no segundo momento, com base nos debates ocorridos na primeira etapa, o professor conduz a explanação do conteúdo necessário à interpretação do problema. É nesse contexto que ocorre o estudo sistemático do conteúdo, em que os conceitos são definidos e os tópicos são relacionados. Já no terceiro momento pedagógico - a aplicação do conhecimento (AC) -, os 
conceitos definidos na etapa anterior são tomados como base para analisar, interpretar e apresentar respostas para o problema inicial. Além dessa retomada, os autores ressaltam que outras situações problemáticas, diferentes da apresentada inicialmente, podem ser colocadas em discussão para que os alunos as interpretem à luz do conteúdo abordado no segundo momento. Essa não é uma condição da abordagem dos 3MP, mas uma possibilidade de ampliar o conteúdo programático, extrapolando as discussões para uma esfera que transcende o cotidiano do aluno (DELIZOICOV; ANGOTTI; PERNAMBUCO, 2011).

Tais atividades proporcionam o contato do estagiário com a escola e seus profissionais, de modo a promover a articulação entre teoria e prática, integrar a universidade e a escola e desenvolver pesquisas relacionadas ao ensino de Química com alunos do Ensino Médio (BROIETTI; STANZANI, 2016). Na rotina da disciplina, constam encontros quinzenais de orientação ocorridos na universidade entre cada estagiário e o(a) professor(a)-formador(a) do curso.

Portanto, a coleta dos dados desta investigação ocorreu nos encontros de orientação para o planejamento e o desenvolvimento de uma AE ( $2 \mathrm{~h} /$ aula $)$ e de uma SD (4 h/aula) sobre o conteúdo de Soluções, ocorridos entre a professora-formadora e uma licencianda, aqui denominada Mary Jane, que foram gravados em áudio e transcritos.

\section{A análise dos dados}

A Análise Textual Discursiva (ATD) de Moraes e Galiazzi (2011) foi empregada nesta investigação para construir significados a partir de um conjunto de textos; o corpus, neste trabalho, é constituído pelas transcrições das discussões ocorridas entre Mary Jane e a professora-formadora durante o planejamento, a implementação e a avaliação das atividades de estágio.

Dois conjuntos de dados são analisados: 1) discussões ocorridas entre Mary Jane e a professora-formadora durante o preparo das atividades; e 2) discussões pós, ocorridas após as aulas serem ministradas na escola. Ambos foram submetidos a cada etapa de análise da ATD, a saber: a desconstrução dos textos do corpus; a unitarização (na qual identificamos unidades de análises em cada conjunto de dados); o estabelecimento de relações entre os elementos unitários, a categorização (que foi construída de forma emergente a partir das unidades de análise identificadas); e o captar o novo emergente em que a nova compreensão é comunicada e validada, apoiando-nos na literatura supracitada que fundamenta esta pesquisa (MORAES; GALIAZZI, 2011).

Do primeiro conjunto de dados emergiram cinco categorias referentes ao conhecimento do conteúdo, e duas ao conhecimento pedagógico do conteúdo, as quais codificamos da seguinte forma: $\mathrm{C} 1(\mathrm{CC}), \mathrm{C} 2(\mathrm{CC}), \ldots$ e $\mathrm{C} 5(\mathrm{CC})$ e $\mathrm{C} 1(\mathrm{PCK})$ e $\mathrm{C} 2(\mathrm{PCK})$, respectivamente. Das categorias originadas do PCK, ainda emergiram subcategorias, que foram codificadas de acordo com a categoria à qual se referem, como por exemplo: C1.1(PCK) representa a subcategoria 1, da categoria 1 referente ao conhecimento pedagógico do conteúdo. Da análise do segundo conjunto de dados, emergiram cinco categorias, que interpretamos como representativas dos conhecimentos desenvolvidos por Mary Jane a partir do seu PCK, mobilizado durante o preparo das atividades; por isso, estabelecemos o código PCKD, que representa o conhecimento pedagógico do conteúdo por ela desenvolvido. Estas, por sua vez, foram codificadas da seguinte forma: $\mathrm{C} 1(\mathrm{PCKD}), \mathrm{C} 2(\mathrm{PCKD})$, ... e $\mathrm{C} 5(\mathrm{PCKD})$, as quais ainda originaram subcategorias, codificadas de acordo com a categoria à qual se referem. Por exemplo, a C1.1(PCKD) representa a subcategoria 1 , da categoria 1 , referente ao PCK desenvolvido.

Moraes e Galiazzi (2011) explicam que o estabelecimento das categorias depende do tipo de metodologia adotada pelo pesquisador, bem como os referenciais teóricos empregados na análise e a interpretação dos dados. Elas podem ser construídas pelo método dedutivo, em que são deduzidas das teorias que fundamentam a pesquisa por meio de um movimento do geral para o particular, ou pelo método indutivo, que consiste na construção das categorias com base no conteúdo dos textos do corpus à medida que o pesquisador se envolve exaustivamente com os materiais textuais, processo que se caracteriza por um caminhar do pesquisador do particular para o geral.

Nesta investigação, a categorização dos conhecimentos de Mary Jane durante o preparo das atividades de estágio permitiu o estabelecimento de categorias denominadas emergentes, que se 
originaram de um processo analítico com base em nosso conhecimento tácito, realizado de forma indutiva do particular para o geral. Foi esse movimento que nos encaminhou até a teoria de Shulman, pois percebemos que a mobilização de conhecimentos por ela realizada durante o preparo das atividades apresentou uma estreita relação com o processo de transformação dos conhecimentos de base em PCK, como explicado por Shulman (1986). Assim, para a análise do segundo conjunto de dados, tomamos como ponto de partida as categorias referentes ao PCK da licencianda, estabelecidas na análise do primeiro conjunto de dados, para buscar unidades de análise que caracterizassem o desenvolvimento do seu PCK após as aulas serem ministradas. Entendemos que o processo de categorização desta investigação ocorreu tanto de forma indutiva quanto dedutiva, sendo que se iniciou de forma indutiva durante a análise do primeiro conjunto de dados, revelando o referencial teórico que poderia sustentar a análise do segundo conjunto de dados, que ocorreu tanto de forma indutiva quanto dedutiva, pois as categorias emergiram de um desdobramento das anteriores e sustentadas pela teoria de Shulman, daí as denominarmos como emergentes.

Por fim, a última etapa da ATD, o captar o emergente, expressa as compreensões atingidas durante todo o processo de análise e será apresentado nos tópicos seguintes.

\section{ANÁLISE E DISCUSSÃO DOS RESULTADOS}

\section{Primeira etapa da análise - as orientações}

Para melhor entendermos como ocorreu o desdobramento das ideias de Mary Jane e a emergência de categorias referentes ao conteúdo e ao conhecimento pedagógico do conteúdo, apresentamos a seguir a análise das suas falas. Tal processo se iniciou com a leitura flutuante dos materiais textuais, as entrevistas, seguido da sua interpretação com base no modelo de PCK de Shulman (1986). Para representá-los, os conjuntos de falas apresentados na sequência foram numerados na ordem em que são retratados na análise, seguidos do código "CQ" de Conteúdo Químico. Iniciando pelas discussões acerca do conteńdo químico, verificamos que a licencianda apontou os conceitos que pretendia trabalhar ao abordar o conteúdo de Soluções, assim como a sua organização nas aulas da AE e da SD:

Mary Jane: Sim, daí eu perguntei para ela o que ela costuma trabalhar em Soluções, daí ela falou que trabalha a parte de cálculo de concentração e a classificação em saturada, insaturada... (1_CQ)

Mary Jane: [...] então eu tinha pensado em fazer mais ou menos assim, fazer a SD com esse tipo de problema para trabalhar a concentração, os cálculos de concentração. (2_CQ)

Mary Jane: [...] aí ela quer que eu faça a aula experimental desse mesmo conteúdo. Eu pensei então em colocar a [aula] experimental no início. Porque daí na experimental dá para trabalhar o básico, soluto, solvente... (3_CQ)

Verificamos, até aqui, que Mary Jane se preocupou em organizar o conteúdo a ser trabalhado, tanto no que diz respeito à maneira quanto ao momento da aula em que os conceitos seriam abordados. Shulman (1986) nos fala que o conhecimento do conteúdo se revela pela quantidade e organização de conhecimento específico na mente do professor. Essa definição é interpretada por Grossman (1990) como sendo o conhecimento dos principais conceitos dentro de uma área de conhecimento, neste caso a Química, e as relações entre eles. Em nosso entendimento, Mary Jane demonstrou conhecer o conteúdo de Soluções e as relações existentes entre cada tópico do assunto, o que possibilitou a organização do conteúdo da AE e da SD.

Posteriormente, Mary Jane fez apontamentos sobre os conceitos de densidade e solubilidade, como vemos a seguir:

Mary Jane: Eu também fiquei em dúvida em uma coisa, a solubilidade também entraria aqui não entraria? Porque se for ver tudo que tem para trabalhar em soluções, tem o conceito de densidade, de solubilidade, muita coisa. [...] porque eu penso que os conceitos de densidade e solubilidade deveriam ser trabalhados separados, uma aula para definir densidade e outra para definir solubilidade. (4_CQ) 
O conhecimento do conteúdo compreende a organização e as relações conceituais existentes dentro de um mesmo conteúdo, assim como as relações entre diferentes conteúdos de uma mesma área (SHULMAN, 1986; GROSSMAN, 1990). Essa definição ajuda-nos a interpretar os apontamentos da licencianda na fala 4_CQ, ficando evidente que ela compreende as relações conceituais existentes dentro do conteúdo de Soluções.

$\mathrm{Na}$ sequência, apresentamos a análise das falas referentes à organižação da Atividade Experimental com caráter investigativo, que foram codificadas seguindo-se o mesmo padrão empregado anteriormente, respeitando-se a ordem em que são mencionadas no processo analítico seguidas do código "AE" de Atividade Experimental. Verificamos, nesse turno de falas, as primeiras discussões sobre a elaboração da situação-problema:

Mary Jane: Mas não pode ser aquela da pessoa não afundar no Mar Morto?

Pesquisadora-formadora: Aquela é boa né: Por que uma pessoa não afunda no Mar Morto? Mary Jane: Mas aí tem a ver com a densidade também.

Pesquisadora-formadora: Então, por isso eu tinha pensado em deixar ela como uma das questões pós-laboratório, pra gente extrapolar a discussão para outro conceito, que é o de densidade. Ou então, vamos usar ela como situação-problema mesmo e aí adaptamos a prática e usamos a rolha de silicone também.

Mary Jane: Mas daí, deixa eu pensar então... o que podemos fazer para encaixar...? (1_AE)

Verificamos que elas discutem os conceitos necessários à solução de uma situação-problema sobre o fato de uma pessoa não afundar no Mar Morto, com vistas à elaboração de uma situaçãoproblema que sustente a abordagem do conteúdo pretendido e delimitado na compreensão inicial da estagiária. Esse movimento permite-nos identificar, claramente, a integração entre o conteúdo químico e a estratégia de ensino, o que nos leva a compreender que a mobilização do seu PCK no planejamento da AE tem como ponto de partida o conhecimento do conteúdo (SHULMAN, 1986). É a partir daí que a professora-formadora e a licencianda encaminham o planejamento para a elaboração dos objetivos de ensino, como vemos a seguir:

Mary Jane: Na verdade esses objetivos eu acho um pouco complexo de colocar tudo que a gente quer. [...] não preciso colocar nada referente a densidade né, porque não é o objetivo.

Pesquisadora-formadora: Não precisa. (2_AE)

Constatamos que, juntas, elas chegaram a um acordo acerca da abordagem do conceito de densidade no decorrer da atividade, que era uma preocupação da licencianda desde o início do planejamento da aula. Então, levando-se em consideração os objetivos propostos, a situação-problema e o conteúdo, chegou-se finalmente à organização das etapas do experimento, como vemos a seguir:

Mary Jane: Então, aí a solução fica saturada, aí tem que colocar mais sal e ele não vai dissolver de novo.

$[\ldots]$

Mary Jane: Então, se a gente for pensar, a partir daí dava para trabalhar com a rolha, né?

Pesquisadora-formadora: Então...

Mary Jane: Porque a partir daí a gente volta a colocar sal até ela saturar de novo.

[...] (3_AE)

Nesse turno de falas, fica ainda mais clara a integração entre o conteúdo específico e a estratégia da experimentação investigativa, à medida que elas pensam nas etapas do experimento com base em cada tópico do conteúdo a ser abordado, revelando que a mobilização do PCK da licencianda está totalmente atrelada ao conteúdo e à sua transformação em conteúdo ensinável, conforme Shulman (1986). Com base no modelo de Grossman (1990), o PCK é apresentado como um conhecimento central entre o conhecimento pedagógico geral, o conhecimento do tema e o conhecimento do contexto, subordinado ao conhecimento dos propósitos (conhecimentos e crenças) acerca do ensino de um 
determinado conteúdo, da compreensão e das concepções dos estudantes, do currículo e das estratégias instrucionais e representações do conteúdo.

Portanto, começamos a construir um entendimento de que, durante o planejamento da AE, a mobilização do PCK de Mary Jane ocorre tendo o conhecimento do conteúdo como ponto de partida, atrelado aos seus propósitos de ensino e ao conhecimento das estratégias instrucionais e representações do conteúdo, ideias que ficaram mais claras nas discussões acerca da elaboração da situação-problema, dos objetivos e das etapas do experimento. Já o conhecimento pedagógico geral e do contexto estão pouco evidentes em suas falas, talvez pela importância dada ao conteúdo em si. Outro ponto importante é que, nessa fase de planejamento da AE, a licencianda não apresentou ideias sobre a compreensão e as concepções dos estudantes, um dos componentes do PCK apresentados tanto por Shulman (1986) quanto por Grossman (1990).

Foi dessa maneira que elas conduziram as discussões para a elaboração das questões póslaboratório, de modo que contemplassem todas as observações experimentais realizadas pelos alunos, os objetivos de ensino, as etapas do experimento, e oferecessem subsídios para a solução da situaçãoproblema, como vemos nos excertos a seguir:

Mary Jane: Isso, eu pensei exatamente isso. Então eu vou pedir na primeira [questão] para definir soluto e solvente.

Pesquisadora-formadora: Sim, aí a segunda pode ser para eles definirem solução. O que é uma solução?

Mary Jane: Certo.

Mary Jane: Isso, aí eu ia perguntar agora, como vamos jogar a densidade na discussão? [...] (4_AE)

Mary Jane: O segundo [objetivo] vai ser discutido na hora da prática.

Pesquisadora-formadora: Isso e a gente pode incluir mais um objetivo específico aqui também, definir o que é solução.

Mary Jane: Ok. (5_AE)

Aqui, a relação entre as compreensões pretendidas por parte dos alunos e as intenções de Mary Jane com todo o planejamento ficam bastante claras, pois que ela percebe a relação entre todos os constituintes do roteiro experimental, bem como a relação entre as suas intenções e as aprendizagens pretendidas para com os alunos. Mais uma vez verificamos que a mobilização do PCK da licencianda se revela por meio dos seus propósitos acerca do ensino e do conhecimento das estratégias instrucionais e representações do conteúdo, sustentados pelo conhecimento do conteúdo específico (SHULMAN, 1986; GROSSMAN, 1990).

Compreendemos que, à medida que a licencianda e a orientadora vão construindo cada parte do roteiro atrelada às discussões anteriores, ocorre um aprofundamento na organização do conteúdo com base nos propósitos de ensino da licencianda e na estratégia de ensino adotada, ou seja, a experimentação investigativa. Logo, constatamos que o PCK de Mary Jane durante o preparo da AE se sustenta pelo conhecimento do conteúdo e se revela pela sua organização e integração à estratégia instrucional adotada, levando-se em consideração seus objetivos de ensino e as aprendizagens pretendidas por parte dos alunos.

Dando seguimento à investigação, apresentamos as falas que representam as discussões para organizar as aulas com base nos Três Momentos Pedagógicos, também codificadas no mesmo padrão seguido anteriormente, respeitando-se a ordem em que são mencionadas no processo analítico, seguidas do código "SD", de Sequência Didática. A seguir, apresentamos as ideias da licencianda acerca da organização do $1^{\circ} \mathrm{MP}$ :

Mary Jane: Então professora, como eu já tinha falado, a professora [regente da escola] pediu para eu trabalhar Soluções, aí na aula passada de Instrumentação a professora [regente da IES] deu uma ideia bem legal que foi uma problematização que ela fez com $\mathrm{NaCl}$, em que ela colocava 3 béqueres com diferentes rotulagens sabe?! Em um tinha 4\%, no outro $4 \mathrm{~g} / \mathrm{L}$ e no outro $4 \mathrm{~mol} / \mathrm{L}$. Então ela perguntava se eles experimentassem se o sabor seria o mesmo nos três. Eu achei bem legal e pensei na possibilidade de a gente trabalhar isso. (1_SD) 
Aqui já percebemos a mobilização do seu PCK no sentido de transformar o conteúdo específico em conteúdo ensinável por meio de uma problematização (SHULMAN, 1986). Além disso, constatamos que Mary Jane se apresenta mais pró-ativa que na elaboração da AE, provavelmente por já ter ministrado as aulas experimentais. Isso nos revela alguns indícios do desenvolvimento do seu PCK, como nos fala Shulman (1986). Ainda assim, a sua preocupação com o conteúdo específico é recorrente durante o planejamento, como podemos constatar:

Mary Jane: [...] Aí eu fiquei pensando se eles não iam ficar um pouco confusos. Por isso eu coloquei justamente o 2,25, porque eu pensei: se 0,9 é para 100, daí eu fiz para 250 para ver quanto que tinha, que é 2,25 , por isso que eu coloquei $2,25 \mathrm{em}$ todos, por causa do frasco de 250. (2_SD).

Observamos que Mary Jane, ao elaborar o problema, atentou para o volume dos frascos de soro fisiológico e refletiu sobre as possíveis interpretações e os questionamentos que pudessem ser realizados pelos alunos no decorrer da aula. Além disso, é interessante destacar que, assim como no preparo da AE, a mobilização do PCK de Mary Jane ocorre tendo como ponto de partida o conhecimento do conteúdo que sustenta a elaboração da problematização inicial, para que esta dê margem à discussão do conteúdo pretendido no segundo momento, evidenciando seus propósitos de ensino (SHULMAN, 1986; GROSSMAN, 1990). Tais reflexões da licencianda nos mostram que o seu PCK durante o planejamento da SD se revela tanto pelas discussões acerca da organização do conteúdo com base nos 3MP, quanto pela preocupação com as concepções e compreensões dos estudantes, elementos do PCK apontados por Shulman (1986) e Grossman (1990).

A discussão da situação-problema é que dá suporte para a licencianda pensar sobre o Segundo Momento Pedagógico, como vemos a seguir:

Mary Jane: Então vou usar esse exemplo para explicar $\mathrm{m} / \mathrm{m}$ e a água oxigenada para explicar v/v, como é mesmo? (3_SD)

Nesse caso, percebemos que seu PCK se revela mais uma vez sustentado pelo conhecimento do conteúdo, porém, orientado pela abordagem dos 3MP e pelos seus propósitos de ensino, como explicado no modelo de Grossman (1990). Além do mais, constatamos que, durante essa fase de planejamento da SD, além da orientação pela abordagem de ensino adotada (os $3 \mathrm{MP}$ ), as crenças e os propósitos de ensino da licencianda ficaram bastante evidentes, elemento que, segundo Grossman (1990), também sustenta o PCK. Percebemos isso tanto na fala 3_SD quanto na que se segue, a 4_SD, quando ela reflete sobre a explanação do conteúdo no $2^{\circ} \mathrm{MP}$ :

Mary Jane: [...] eu só estou em dúvida quanto a uma coisa, eu não sei se eu apresento para eles aquelas fórmulas também que tem para calcular a concentração, para eles irem jogando direto. Mas, eu penso que fórmula, não sei, para mim não é muito conveniente porque daí eles não vão aprender a aplicar sabe. Eu acho que se eu passar tudo por regra de três acho que dá para eles compreenderem melhor, assimilar melhor, mas eu não sei se é conveniente apresentar as fórmulas, o que você acha? (4_SD).

Observamos nas falas do conjunto 3_SD que Mary Jane se preocupa em explanar o conteúdo a partir de exemplos de produtos conhecidos pelos alunos e, para isso, pede ajuda à professoraformadora para delimitar um exemplo para cada tipo de concentração, de modo a englobar todas as unidades abordadas no problema inicial. Já na fala 4_SD, percebemos que a licencianda reflete sobre a forma como irá explicar os cálculos e as conversões, revelando suas ideias a respeito do uso de fórmulas matemáticas. Percebemos que, em ambos os turnos de falas, o PCK de Mary Jane continua a se revelar sustentado pelo conhecimento do conteúdo; no entanto, isso ocorre tendo por base o contexto, o que se evidencia quando ela busca produtos do cotidiano dos alunos e em um modelo de ensino de construção de conhecimentos, quando ela pensa sobre a utilização de regra de três simples, ao invés do emprego de fórmulas matemáticas. Fica evidente que aqui seus propósitos de ensino se revelam pela 
relação entre o conhecimento do conteúdo e o conhecimento do contexto, sendo este segundo referente ao conhecimento dos alunos, das comunidades e das culturas (SHULMAN, 1987; GROSSMAN, 1990).

Tais relações nos aproximam do modelo de Grossman (1990), que posiciona o PCK como um conhecimento central entre o conhecimento pedagógico geral, o conhecimento do tema e do contexto, também aparecendo na elaboração da atividade do $3^{\circ} \mathrm{MP}$, como podemos ver a seguir:

Mary Jane: Tá. Aí para trabalhar o mol eu pensei em preparar uma solução de bicarbonato de sódio. Aí eu coloco um rótulo no frasco da solução.

$[\ldots]$

Mary Jane: Eu pensei em bicarbonato porque é um produto mais próximos deles né, que usamos no dia a dia. [...] é porque peguei produtos que eles consomem, vinagre, coca-cola para ver a concentração de açúcar, até cerveja para ver a concentração de álcool. (5_SD).

Verificamos que, nessa etapa de transformação do conteúdo, ela novamente mobiliza o conhecimento de contexto durante a escolha dos produtos que serão utilizados na realização da atividade, evidenciando a relação entre o conhecimento do conteúdo e o de contexto (SHULMAN, 1986; GROSSMAN, 1990). Na fala que se segue, por outro lado, além da relação entre esses conhecimentos da base, percebemos ainda a mobilização do conhecimento pedagógico geral, quando a licencianda reflete sobre a organização dos alunos em grupos:

Mary Jane: Não não, se deixar solto com certeza não. Porque tem muitos componentes em cada produto. Tem que deixar especificado, eu tinha pensado nisso também. Peguei até o shoyu que tem alta concentração de sódio. Só que está em miligramas. Aí pensei em dividir em 5 grupos, mas só um teria produto em quantidade de matéria porque só vai ter o bicarbonato.

[...]

Mary Jane: Então eu vou pedir para eles além de interpretar o rótulo, para converter em outra unidade. Aí eu vou levar então a solução de bicarbonato, a cerveja, o vinagre, a água oxigenada e o álcool. Pode ser, né?

Pesquisadora-formadora: Isso, está ótimo. Aí fecha esse terceiro momento. (6_SD).

Nesse turno de falas, destacamos a preocupação de Mary Jane com a gestão da turma, que se revela pela mobilização do conhecimento pedagógico geral, referindo-se a princípios, estratégias e habilidades gerais relacionadas ao ensino (SHULMAN, 1987; GROSSMAN, 1990). Nesse caso, ainda que seu planejamento se sustente no conhecimento do conteúdo, percebemos que a estratégia de ensino adotada exerceu forte influência na sua tomada de decisões, de modo que o desdobramento de suas ideias ocorreu a partir da inter-relação entre o conhecimento do conteúdo e a abordagem de ensino. Portanto, compreendemos que, nessa fase do planejamento, Mary Jane integrou o conhecimento específico à abordagem de ensino empregada, ao passo que a mobilização de conhecimentos acerca do contexto, dos alunos, do currículo, da disciplina etc. aconteceu à medida que ela foi refinando suas intenções e seus propósitos de ensino.

Essa inter-relação é que sinaliza para a licencianda a necessidade de mobilização de outros conhecimentos, como o pedagógico geral e o de contexto, tal como nos fala Grossman (1990). Ao contrário do preparo da $\mathrm{AE}$, no peparo da $\mathrm{SD}$ a licencianda se preocupou mais em contextualizar o ensino e preconizou a gestão e o gerenciamento da turma, o que pode ter ocorrido devido à experiência já vivenciada na realização da $\mathrm{AE}$ ou pelas próprias características da abordagem dos $3 \mathrm{MP}$. Compreendemos, assim, que a análise das orientações com a professora-formadora nos possibilitou identificar e caracterizar os conhecimentos desenvolvidos por Mary Jane durante o preparo das atividades de estágio, o que, de acordo com as nossas interpretações, foram revelados na forma de categorias pertencentes ao conhecimento do conteúdo e ao conhecimento pedagógico do conteúdo (SHULMAN, 1986; GROSSMAN, 1990).

No Quadro 1, podemos verificar exemplos da categorização das falas da licencianda a partir das categorias e subcategorias que emergiram da análise. 
Quadro 1 - Categorização das falas de Mary Jane no decurso das orientações

\begin{tabular}{|c|c|c|}
\hline \multicolumn{3}{|c|}{ CONHECIMENTO DO CONTEÚDO } \\
\hline \multicolumn{2}{|c|}{ Categorias/Subcategorias } & Exemplos de excertos de falas \\
\hline \multicolumn{2}{|c|}{$\begin{array}{l}\text { C1(CC) - Conceitos químicos a serem } \\
\text { ensinados }\end{array}$} & "[...] cálculo de concentração e a classificação em saturada, insaturada..." (1_CQ) \\
\hline \multicolumn{2}{|c|}{ C2(CC) - Conteúdo da SD } & $\begin{array}{l}\text { "[...] fazer a SD com esse tipo de problema para trabalhar a concentração, os cálculos } \\
\text { de concentração" (2_CQ) }\end{array}$ \\
\hline \multicolumn{2}{|c|}{ C3(CC) - Conteúdo da AE } & "[...] dai na experimental dá para trabalhar o básico, soluto, solvente..." (3_CQ) \\
\hline \multicolumn{2}{|c|}{ C4(CC) - Outros conceitos químicos } & $\begin{array}{l}\text { "Eu também fiquei em dúvida em uma coisa, a solubilidade também entraria aqui não } \\
\text { entraria?" (4_CQ) }\end{array}$ \\
\hline \multicolumn{2}{|c|}{$\begin{array}{l}\text { C5(CC) - Relação entre os conceitos } \\
\text { químicos }\end{array}$} & $\begin{array}{l}\text { "[...] se for ver tudo que tem para trabalhar em solucões, tem o conceito de densidade, de } \\
\text { solubilidade, muita coisa". (4_CQ) }\end{array}$ \\
\hline \multicolumn{3}{|c|}{ CONHECIMENTO PEDAGÓGICO DO CONTEÚDO (PCK) } \\
\hline \multirow{4}{*}{ 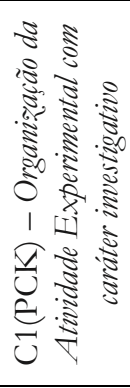 } & $\begin{array}{l}\text { C1.1(PCK) - Construindo a } \\
\text { situação-problema }\end{array}$ & $\begin{array}{l}\text { "Mas não pode ser aquela da pessoa não afundar no Mar Morto?"; "Mas aí tem a ver } \\
\text { com a densidade também". (1_AE) }\end{array}$ \\
\hline & $\begin{array}{l}\text { C1.2(PCK) - Estabelecendo } \\
\text { os objetivos }\end{array}$ & $\begin{array}{l}\text { "[...] não preciso colocar nada referente a densidade né, porque não é o objetivo". (2_AE) } \\
\text { "O segundo vai ser discutido na hora da prática". (5_AE) }\end{array}$ \\
\hline & $\begin{array}{l}\text { C1.3(PCK) - Organizando } \\
\text { as etapas do experimento }\end{array}$ & $\begin{array}{l}\text { "Então, aí a solução fica saturada, aí tem que colocar mais sal e ele não vai dissolver de } \\
\text { novo"; "Então, se a gente for pensar, a partir dai dava para trabalhar com a rolha, né" } \\
\text { (3_AE) }\end{array}$ \\
\hline & $\begin{array}{l}\text { C1.4(PCK) - Elaborando as } \\
\text { questões pós-laboratório }\end{array}$ & $\begin{array}{l}\text { "[...] eu vou pedir na primeira para definir soluto e solvente". } \\
\text { "[...] como vamos jogar a densidade na discussão?" (4_AE) }\end{array}$ \\
\hline \multirow{3}{*}{ 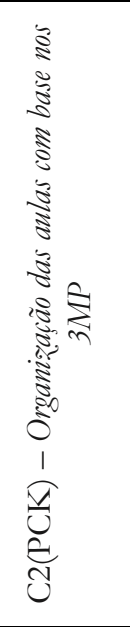 } & $\begin{array}{l}\mathrm{C} 2.1(\mathrm{PCK})-\text { Pensando no } \\
1^{\circ} \mathrm{MP}\end{array}$ & $\begin{array}{l}\text { "[...]Em um tinha 4\%, no outro } 4 g / L \text { e no outro } 4 \text { mol/L. Então ela perguntava se } \\
\text { eles experimentassem se o sabor seria o mesmo nos três. Eu achei bem legal e pensei na } \\
\text { possibilidade de a gente trabalhar isso". (1_SD) } \\
\text { "[...] porque todas as embalagens são de } 250 \text {, né. Ai eu fiquei pensando se eles não iam } \\
\text { ficar um pouco confusos. Por isso eu coloquei justamente o 2,25..." (2_SD) }\end{array}$ \\
\hline & $\begin{array}{l}\text { C2.2(PCK })- \text { Pensando no } \\
2^{\circ} \mathrm{MP}\end{array}$ & $\begin{array}{l}\text { "Então vou usar esse exemplo para explicar } m / m \text { e a água oxigenada para explicar } \\
v / v . . . " \text { (3_SD) } \\
\text { "[...] eu não sei se eu apresento para eles aquelas fórmulas também que tem para calcular } \\
\text { a concentração, para eles irem jogando direto...”. (4_SD) }\end{array}$ \\
\hline & $\begin{array}{l}\mathrm{C} 2.3(\mathrm{PCK})-\text { Pensando no } \\
3^{\circ} \mathrm{MP}\end{array}$ & $\begin{array}{l}\text { "[...] Aí para trabalhar o mol eu pensei em preparar uma solução de bicarbonato de } \\
\text { sódio..."; "[...]. "Eu pensei em bicarbonato porque é um produto mais próximos deles, } \\
\text { né, que usamos no dia a dia". (5_SD) } \\
\text { "Então eu vou pedir para eles além de interpretar o rótulo, para converter em outra } \\
\text { unidade. Aí eu vou levar então a solução de bicarbonato, a cerveja, o vinagre, a água } \\
\text { oxigenada e o álcool. Pode ser, né". (6_SD) }\end{array}$ \\
\hline
\end{tabular}

Fonte: adaptado de Arrigo (2021, p. 160).

No Quadro 1, temos uma síntese da análise das falas de Mary Jane durante o planejamento das aulas. Como já apontado, verificamos que, durante o preparo da AE, a mobilização do PCK da licencianda se revela por meio dos seus propósitos acerca do ensino e do conhecimento das estratégias instrucionais e representações do conteúdo, sustentados pelo conhecimento do conteúdo específico, ficando o conhecimento pedagógico geral e o do contexto pouco evidentes nessa fase. No preparo da $\mathrm{SD}$, assim como no preparo da AE, percebemos que o ponto de partida para as reflexões é sempre o conhecimento do conteúdo, que sustentou a elaboração de cada momento pedagógico. No entanto, a licencianda faz apontamentos também sobre o contexto e as questões pedagógicas de âmbito geral, além de levar em consideração as concepções dos estudantes. Logo, compreendemos que a abordagem de ensino adotada exerceu forte influência na sua tomada de decisões durante o planejamento, de modo que o desdobramento de suas ideias ocorreu a partir da inter-relação entre o conhecimento do conteúdo e o das estratégias de ensino; e essa inter-relação, por sua vez, é que sinaliza a necessidade de mobilização de outros conhecimentos, como o pedagógico geral e o de contexto, tal como preconiza Grossman (1990). 
Esses entendimentos parecem nos encaminhar ao modelo integrativo proposto por GessNewsome (1999), em que o PCK não é entendido como um domínio de conhecimento e se constrói pela intersecção do conhecimento pedagógico, do tema e do contexto. Apesar de o conhecimento do contexto e o pedagógico geral não terem ficado tão evidentes nas falas da licencianda durante o preparo da $\mathrm{AE}$, entendemos que eles fizeram parte do planejamento, mesmo que de forma implícita, ao passo que podem ter se revelado com mais clareza no preparo da SD em virtude das características da própria abordagem dos 3MP, ou pelo fato de Mary Jane já ter realizado a atividade experimental, propiciando um contato inicial com a turma.

Gess-Newsome (1999) registra que, no modelo integrativo, o ato de ensino ocorre pela apresentação do conteúdo a partir de algum contexto, empregando-se uma forma apropriada de ensino. Entendemos, assim, que Mary Jane tomou como ponto de partida o conteúdo de Soluções, apropriouse dos princípios da experimentação investigativa e dos 3MP e estabeleceu um contexto para embasar a explanação do conteúdo. No caso da $\mathrm{AE}$, o contexto que sustentou as elaborações conceituais foi o índice de salinidade do Mar Morto, tema da situação-problema. $\mathrm{Na} S \mathrm{D}$, a concentração de $\mathrm{NaCl}$ em soro fisiológico é que embasou a problemática inicial e norteou as outras etapas da sequência.

Portanto, pelo fato de ter sido possível identificar em vários momentos das suas falas os conhecimentos do conteúdo, do contexto e o pedagógico geral e a relação estabelecida entre eles, concluímos que, durante a fase de planejamento, o PCK da licencianda se desenvolveu pela integração, e não pela transformação desses três construtos; por isso, identificamos semelhanças com o modelo integrativo, ao invés do transformativo (GESS-NEWSOME, 1999).

\section{Segunda etapa da análise - as discussões pós}

Nesta etapa, iniciamos a primeira leitura das falas de Mary Jane buscando os conhecimentos por ela desenvolvidos a partir do conhecimento pedagógico do conteúdo, identificado na análise das orientações para o preparo das atividades. Esse movimento deu origem a cinco categorias: Aprendiragem, Participação, Planejamento, Interação professor-aluno e Mediação Pedagógica do Conteúdo, que serão apresentadas e discutidas a seguir. Para codificá-las, utilizamos os símbolos " $\mathrm{A}$ " de Aprendizagem, "P" de Participação, "PL" de Planejamento, "IPA" de Interação professor-aluno e "MPC" de Mediação Pedagógica do Conteúdo. Já os turnos de falas foram numerados na ordem em que são retratados.

Com relação à categoria Aprendizagem, Mary Jane apresentou compreensões sobre facilidades e dificuldades dos alunos, como vemos nos excertos a seguir:

Pesquisadora-formadora: foi só um grupo que chegou nisso?

Mary Jane: foram dois que conseguiram, aquela menininha do canto, sabe? Ela falou que esse por cento era alguma coisa de 100 , mas não falavam $\mathrm{mL}$, eles falavam que esse $0,9 \mathrm{~g}$ estava em alguma coisa de 100. (1_A)

Mary Jane: Só que assim, na discussão eles são muito bons, mas na hora dos cálculos eu observei agora que eles fazem tudo sem unidade, tipo 80 para 1000, daí eles não sabem o que é. Aí chega na segunda regra de três e eles não sabem o que tinham na primeira. Igual à do $\mathrm{NaCl}$, era $3,5 \mathrm{~g} / \mathrm{L}$ para transformar para 500mL, são 3,5g em 1000mL e em 500? Daí ela colocou tudo sem unidade, então quando foi para transformar para mol ela se perdeu, não sabia qual valor pegar. (2_A)

A percepção de Mary Jane foi que os alunos demonstraram facilidade para interpretar o problema do soro fisiológico, no entanto, apresentaram dificuldade em relacionar e manter as unidades durante os cálculos. Assim, compreendemos que os conjuntos de falas 1_A e 2_A revelam o desenvolvimento do PCK da licencianda por meio de um processo de verificação das compreensões dos alunos, um dos componentes do PCK segundo o modelo de Shulman (1986). Trata-se, portanto, da construção de entendimentos acerca das ações dos alunos em relação à atividade proposta e os encaminhamentos didáticos por ela adotados, que implicam também a construção de conhecimento do contexto, que, segundo Grossman (1990), é uma esfera do conhecimento dos professores que inclui o conhecimento dos alunos. Mais evidências da construção desse conhecimento estão retratadas na fala a seguir: 
Mary Jane: Sim, deu sim. É que parece que eles não têm costume de usar as unidades de medida sabe, jogam tudo solto. Outra coisa, eles estão muito acostumados com fórmula, a menina perguntou para mim: Qual é a fórmula que eu posso usar aqui? (3_A)

Percebemos que a utilização de fórmulas para realizar cálculos parece ser uma prática recorrente no cotidiano escolar dos alunos. Com relação a isso, a licencianda já havia feito apontamentos durante a fase de planejamento, no turno de falas 4_SD. Assim, verificamos que a licencianda estabelece uma conexão entre os seus propósitos de ensino e os resultados da sua ação docente, indicando um processo de avaliação e validação da própria prática, o que fica mais evidente, ainda, na fala a seguir:

Mary Jane: Mas também, se eles saírem dali, mesmo com dúvidas nos cálculos e nas conversões, mas se conseguirem pegar e interpretar um rótulo, isso já é muito válido. Se eles virem lá o 4\% e entenderem que são 4 gramas em $100 \mathrm{~mL}$ já é totalmente válido. (4_A)

Parece-nos que a construção de novas compreensões acerca da sua prática ocorre pela validação do seu planejamento com base nos resultados das suas ações, que nos revelam indícios de uma ampliação do seu PCK a partir das experiências práticas vivenciadas, como assinala Shulman (1987) sobre o desenvolvimento do PCK por meio da transformação dos conhecimentos de base e do diálogo com a própria prática. É nessa perspectiva que caminham as discussões a seguir, nas quais podemos verificar constatações da licencianda que nos levaram a estabelecer a categoria Participação, referindo-se ao envolvimento dos alunos durante as aulas, bem como à resolução do problema inicial da SD, retratado a seguir:

Mary Jane: Sim, eles são muito bons, né? Eles discutem, expõem as ideias mesmo que seja coisa errada.

Pesquisadora-formadora: E o espaço de discussão que o problema deu, né, deu mais discussão do que a gente esperava não deu?

Mary Jane: Deu, eu também achei. E você viu que eles bateram no 250mL? (5_P)

Destacamos aqui que Mary Jane ressaltou a discussão sobre o volume dos frascos de soro um dos pontos por ela levados em consideração durante o planejamento, retratado no turno de falas 2_SD. Nesse caso específico, podemos identificar um processo de validação do seu planejamento, em que a licencianda avalia e elogia a participação dos alunos quando menciona a tentativa deles de solucionar o problema, assim como a sua própria ação, ao ressaltar a discussão sobre o volume do frasco de soro, ficando evidente sua percepção acerca da importância de ter se preparado para tal situação durante o planejamento.

Assim, constatamos que um ambiente favorável à participação contribui para o aprendizado dos alunos, pois foi exatamente isso que possibilitou que a licencianda verificasse algumas habilidades e dificuldades por eles apresentadas durante a resolução das atividades propostas, como destacado nas falas a seguir:

Mary Jane: [...] Eu já sabia que era uma turma boa, mas eu não imaginava que eles iam discutir e participar desse jeito. É uma coisa nova para eles solucionar problemas, eles não fazem isso e estão se propondo a discutir, encontrar uma solução. Eu fiquei muito surpresa com o grupo lá que eu dei para comparar $2,21 \mathrm{mg} / \mathrm{L}$ para comparar com o valor $0,05 \mathrm{~mol} / \mathrm{L}$ e eles fizeram o contrário!!! Ao invés de pegar o $\mathrm{mg} / \mathrm{L}$ eles foram no mol/L e fizeram ao contrário. [...] (6_P)

Nesse caso, percebemos que Mary Jane faz uma avaliação da participação dos alunos, que culmina em uma reflexão acerca da influência que a atividade de solucionar uma problemática exerceu sobre o envolvimento e o interesse da turma, assim como a influência da realização de uma atividade experimental, como retratado nos turnos de falas a seguir: 
Mary Jane: Ah, assim, hoje eles ficaram instigados sim, mas lá manuseando, fazendo o experimento, vendo o que está acontecendo sabe, eu acho que eles ficaram mais motivados. (7_P)

Mary Jane: Acho que é por ser uma coisa próxima deles, por isso chama a atenção, porque a principal reclamação dos alunos é sempre aquilo, estou estudando isso para que? Então eu acho que ter um tema é importante, tem que aproximar da realidade deles, como nós fizemos com os rótulos para trabalhar soluções. Então para trabalhar usando a abordagem possibilita que eles interajam, que eles se interessem, participem, a problematização chama a atenção, eles ficam instigados, curiosos, você viu né, eles ficaram curiosos, instigados, envolvidos. (8_P)

Tais reflexões indicam a construção de novos entendimentos acerca da disciplina, das estratégias de ensino, dos alunos e da sua própria prática, o que ocorre pela validação do seu planejamento e dos seus propósitos de ensino com base nos resultados das suas ações. É interessante percebermos que a licencianda constrói entendimentos acerca das contribuições de se utilizar um tema para abordar o conteúdo, de se ter uma problemática a ser solucionada para incentivar a participação dos estudantes e de se fazer uso de estratégias de ensino que aproximem o conteúdo da realidade dos alunos, como na atividade de interpretação dos rótulos de produtos comerciais.

Isso indica que, mesmo que o seu PCK durante as orientações tenha se sustentado pelo conhecimento específico, o conhecimento pedagógico geral e o de contexto, destacados por Grossman (1990) em seu modelo, contribuem para a transformação do conteúdo em conhecimento ensinável, culminando em resultados satisfatórios em termos de aprendizagem e participação dos alunos, como verificamos nas discussões até aqui. Constatamos, portanto, indícios de uma ampliação do seu PCK a partir das experiências práticas vivenciadas, como nos fala Shulman (1987) sobre o desenvolvimento do PCK por meio da transformação dos conhecimentos de base e do diálogo com a própria prática.

Essas considerações nos revelam a importância e a necessidade do planejamento de cada momento da aula, de como o conteúdo será trabalhado, quais estratégias serão empregadas, bem como serão mediadas as interações e elaborações conceituais. Portanto, estabelecemos a categoria denominada Planejamento, na qual alocamos as falas da licencianda em que ela apresenta reflexões acerca do ato de planejar. Com relação à importância de se preparar, de estudar e de organizar um planejamento que norteie a sua ação, Mary Jane teceu as seguintes considerações:

Mary Jane: Ah, eu não sei como são os outros alunos, mas eu me preparo, eu não vou para a aula sem estudar, eu vou com um roteiro do que eu vou fazer para eu não me perder. (9_PL)

Percebemos, pelas falas acima, a importância atribuída por Mary Jane ao planejamento e à elaboração de um roteiro para nortear sua prática durante as aulas. Isso corrobora o que foi discutido durante a análise das orientações e que está sintetizado no Quadro 1, no qual podemos observar que, tanto no preparo da $\mathrm{AE}$ quanto da $\mathrm{SD}$, ela preconizou a construção detalhada de cada momento das aulas, os exemplos que seriam utilizados na explicação do conteúdo, os objetivos, as aprendizagens pretendidas pelos alunos, as atividades a serem propostas, as estratégias de ensino, a organização da turma e a explanação do conteúdo. Todo esse movimento é por ela validado quando ela reflete sobre as contribuições do planejamento, como nas falas que se seguem:

Mary Jane: [...] eu gosto muito de ter um roteiro, então eu acho que essa divisão ela dá um rumo, no primeiro momento eu vou fazer assim, tentar levantar tais ideias, aí no segundo eu vou discutir isso, isso e isso e no terceiro vou aplicar. Eu acho que essa organização facilita e ajuda muito a conduzir a aula, [...] (10_PL)

Mary Jane: Isso que eu achei. E por isso que é importante dar uma aula experimental.

Pesquisadora-formadora: Ah, mas não é por isso que precisamos trabalhar com experimentação em todas as aulas.

Mary Jane: Não, claro que não. Nós trabalhamos com experimentação para dar uma introdução do conteúdo, agora a gente tem que ir para a sala de aula porque precisa também dessa parte conceitual. (11_PL) 
Entendemos que essa importância atribuída por Mary Jane ao planejamento está atrelada ao seu reconhecimento das contribuições dos métodos de ensino empregados nas aulas, tanto da AE quanto da SD. Percebemos nas falas 10_PL e 11_PL as reflexões de Mary Jane sobre a gestão do conteúdo e das atividades com base nos métodos de ensino empregados. Já na fala seguinte, ficam evidentes as suas percepções sobre a gestão dos alunos:

Mary Jane: Eu fiquei com medo ali na hora da lista [de exercícios] de eles dispersarem, por isso que eu pedi para cada aluno ficar responsável por um exercício, porque daí todo mundo fica fazendo alguma coisa, todo mundo trabalha. (12_PL)

A gestão dos alunos é algo que já havia sido pontuado por Mary Jane durante o planejamento, especificamente no turno de falas 6_SD. Nesse caso, verificamos mais uma vez os processos de avaliação e validação que a licencianda faz das suas decisões e ações, que implicam o desenvolvimento do seu PCK por meio de um diálogo com a própria prática (SHULMAN, 1987). Tais evidências desse diálogo consigo mesma ficam ainda mais evidentes nas falas alocadas nas categorias Interação professor-aluno e Mediação Pedagógica do Conteúdo.

A categoria Interação professor-aluno diz respeito às contribuições da interação entre os alunos e a licencianda e entre os próprios alunos, tanto para a realização das atividades quanto para a compreensão do conteúdo, que em nosso entendimento ocorreram devido à atitude de Mary Jane de tentar construir um diálogo interativo com a turma. Sobre a importância da explicação do professor, Mary Jane apresentou as seguintes constatações:

Pesquisadora-formadora: E você viu como é, depois da discussão do problema você foi para o quadro explicar, foi uma parte expositiva, você acha que essa parte da aula ficou ruim?

Mary Jane: Claro que não. Eles precisam da explicação do professor, e é isso mesmo a proposta dos três momentos, não é?! (13_IPA)

Mary Jane: Sim! Eles percebem que eu preciso das respostas deles durante a aula. Pesquisadora-formadora: Claro porque se eles não participam a sua aula vai por água abaixo. Mary Jane: Sim, e na verdade deveria ser assim sempre né, não só nesse momento que a gente vai lá e faz uma intervenção diferente, deveria ser assim sempre. (14_IPA)

Verificamos, aqui, uma concepção construída por Mary Jane sobre a necessidade de explicar o conteúdo aos alunos. No entanto, entendemos que isso não se aplica somente ao momento em que ela apresentou os conceitos de forma expositiva, e, sim, a todo movimento de abordagem realizado durante a aula, em que ela problematizou o conteúdo, deu espaço para os alunos exporem suas ideias, mediou as discussões, explanou sobre o conceito de Soluções e oportunizou a eles (re)construirem suas ideias prévias. Com isso, constatamos que o desenvolvimento do seu PCK se revela aqui pela construção da concepção de que a participação intelectual dos alunos e as intervenções do professor na explanação do conteúdo devem ocorrer, concomitantemente, durante as aulas, conduzindo a um diálogo interativo com vistas à construção de novos conhecimentos pelos alunos (SHULMAN, 1986).

Por isso, a quinta e última categoria, denominada Mediação Pedagógica do Conteúdo, abrange tanto as constatações da licencianda que englobam as categorias anteriormente apresentadas, como as discussões ocorridas durante as orientações. Percebemos, aqui, claramente, a ampliação do PCK da licencianda pela validação da sua prática, ou seja, a construção de novas compreensões acerca da docência (SHULMAN, 1987). Tais constatações da licencianda podem ser verificadas nas falas que se seguem:

Mary Jane: [...] Se eu tivesse chegado lá e falado assim, a concentração em título é isso, a concentração em quantidade de matéria é isso... eles iam no máximo usar a fórmula, fazer uns cálculos, mas não iam conseguir associar nada, iam sair de lá: [...] (15_MPC)

Mary Jane: [...] uma problemática relacionada a um tema instiga mais eles, eu acho que eles se envolvem mais porque está mais relacionada ao dia a dia deles. (16_MPC)

Mary Jane: Olha, eu acho que em relação a essa aproximação deles com o cotidiano, utilizar uma temática, trabalhar os rótulos, faz toda diferença. Principalmente a análise dos rótulos, eles 
ficaram interessados, interpretaram a concentração do refrigerante, da lata de cerveja, do álcool... eu achei que ficou muito bom, mas a turma ajudou também né. (17_MPC)

Mary Jane: Ia ficar aquela decoreba, né: "ah eu sei que têm as três soluções, uma é assim, a outra é assim e a outra é assado, mas eu não sei onde isso está presente”. Mas assim, até quando eles forem preparar um suco eles vão saber que estão preparando uma solução [...] (18_MPC)

Constatamos que as reflexões acima resultam na construção de novos entendimentos acerca da docência a partir do que foi vivenciado em sala de aula, que, para nós, se refere à própria prática da licencianda e representa as suas constatações no tocante ao que foi planejado, desenvolvido e percebido em relação à sua ação docente, que desde o início se evidenciou conduzida pelo conhecimento do conteúdo e em como transformá-lo em conhecimento ensinável (SHULMAN, 1986). Posto isso, apresentamos no Quadro 2 a categorização de alguns excertos das falas de Mary Jane a partir das categorias e subcategorias que emergiram da análise descrita.

Quadro 2 - Categorização das falas de Mary Jane após a realização das atividades

\begin{tabular}{|c|c|c|}
\hline \multicolumn{3}{|r|}{ PCK DESENVOLVIDO } \\
\hline \multicolumn{2}{|r|}{ Categorias/Subcategorias } & Exemplos de excertos de falas \\
\hline \multirow{4}{*}{ 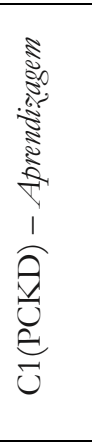 } & $\begin{array}{l}\text { C1.1(PCKD) - Habilidades } \\
\text { para resolver o problema } \\
\text { inicial }\end{array}$ & $\begin{array}{l}\text { "Ela falou que esse por cento era alguma coisa de 100, mas não falavam mL, eles falavam } \\
\text { que esse 0,9g estava em alguma coisa de 100”. (1_A) }\end{array}$ \\
\hline & $\begin{array}{l}\text { C1.2(PCKD) - Dificuldades } \\
\text { para relacionar as unidades }\end{array}$ & $\begin{array}{l}\text { "[..] na discussão eles são muito bons, mas na hora dos cálculos eu observei agora que eles } \\
\text { fazem tudo sem unidade, tipo } 80 \text { para } 1000 \text {, dai eles não sabem o que é". (2_A) }\end{array}$ \\
\hline & $\begin{array}{l}\text { C1.3(PCKD) - Necessidade de } \\
\text { ter uma fórmula para realizar } \\
\text { os cálculos }\end{array}$ & $\begin{array}{l}\text { "[...] eles estão muito acostumados com fórmula, a menina perguntou para mim: Qual é } \\
\text { a fórmula que eu posso usar aqui?". (3_A) }\end{array}$ \\
\hline & $\begin{array}{l}\text { C1.4(PCKD) - Aprendizagem } \\
\text { esperada do conteúdo }\end{array}$ & $\begin{array}{l}\text { "[...] se eles saírem dali, mesmo com dúvidas nos cálculos e nas conversões, mas se } \\
\text { conseguirem pegar e interpretar um rótulo, isso já é muito válido. Se eles virem lá o } 4 \% \text { e } \\
\text { entenderem que são } 4 \text { gramas em } 100 \mathrm{~mL} \text {, já é totalmente válido". (4_A) }\end{array}$ \\
\hline \multirow{4}{*}{ 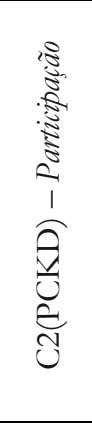 } & $\begin{array}{l}\text { C2.1(PCKD) - Resolução do } \\
\text { problema inicial da SD }\end{array}$ & $\begin{array}{l}\text { "[...] eles são muito bons, né. Eles discutem, expõem as ideias mesmo que seja coisa } \\
\text { errada"; "E você viu que eles bateram no } 250 \mathrm{~mL} \text { ?" (5_P) }\end{array}$ \\
\hline & $\begin{array}{l}\mathrm{C} 2.2(\mathrm{PCKD}) \text { - Resolução das } \\
\text { atividades propostas na SD }\end{array}$ & $\begin{array}{l}\text { "Eu já sabia que era uma turma boa, mas eu não imaginava que eles iam discutir e } \\
\text { participar desse jeito. É uma coisa nova para eles solucionar problemas, eles não fazem } \\
\text { isso e estão se propondo a discutir, encontrar uma solução[...]". (6_P) }\end{array}$ \\
\hline & $\begin{array}{l}\text { C2.3(PCKD) - Realização da } \\
\text { atividade experimental }\end{array}$ & $\begin{array}{l}\text { "[...] hoje eles ficaram instigados sim, mas lá manuseando, fazendo o experimento, vendo } \\
\text { o que está acontecendo sabe, eu acho que eles ficaram mais motivados". (7_P) }\end{array}$ \\
\hline & $\begin{array}{l}\text { C2.4(PCKD) - Utilização de } \\
\text { abordagens com uma } \\
\text { problemática }\end{array}$ & $\begin{array}{l}\text { "Então para trabalhar usando a abordagem possibilita que eles interajam, que eles se } \\
\text { interessem, participem, a problematização chama a atenção, eles ficam instigados, } \\
\text { curiosos...". (8_P) }\end{array}$ \\
\hline \multirow{4}{*}{ 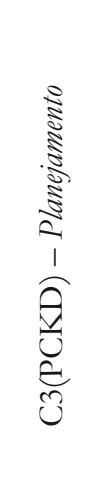 } & $\begin{array}{l}\text { C3.1(PCKD) - Importância de } \\
\text { estudar e se planejar }\end{array}$ & $\begin{array}{l}\text { "[...] eu me preparo, en não vou para a aula sem estudar, eu vou com um roteiro do que } \\
\text { eu vou fazerpara eu não me perder". (9_PL) }\end{array}$ \\
\hline & $\begin{array}{l}\text { C3.2(PCKD) - Contribuições } \\
\text { dos 3MP para organizar o } \\
\text { conteúdo }\end{array}$ & $\begin{array}{l}\text { "[...] eu acho que essa divisão ela dá um rumo, no primeiro momento eu vou fazer assim, } \\
\text { tentar levantar tais ideias, aí no segundo eu vou discutir isso, isso e isso e no terceiro vou } \\
\text { aplicar..." (10_PL) }\end{array}$ \\
\hline & $\begin{array}{l}\text { C3.3(PCKD) - Contribuições } \\
\text { da atividade experimental para } \\
\text { organizar o conteúdo }\end{array}$ & $\begin{array}{l}\text { "E por isso que é importante dar uma aula experimental"; "[...] Nós trabalhamos com } \\
\text { experimentação para dar uma introdução do conteúdo..." (11_PL) }\end{array}$ \\
\hline & $\begin{array}{l}\text { C3.4(PCKD) - Gestão dos } \\
\text { alunos, do conteúdo e das } \\
\text { atividades }\end{array}$ & $\begin{array}{l}\text { "Eu acho que essa organização facilita e ajuda muito a conduðir a aula, porque imagina, } \\
\text { vocêpega todo aquele conteúdo e pensa: "Por onde vou começar? Por onde vou terminar?" } \\
\text { (10_PL); "....] eu pedi para cada aluno ficar responsável por um exercício, porque daí } \\
\text { todo mundo fica faz̧endo alguma coisa..." (12_PL) }\end{array}$ \\
\hline \multirow{3}{*}{ 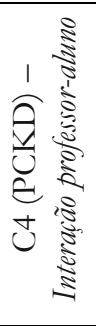 } & $\begin{array}{l}\text { C4.1(PCKD) - Importância da } \\
\text { explicação do professor }\end{array}$ & $\begin{array}{l}\text { "[...] Eles precisam da explicação do professor, e é isso mesmo a proposta dos três } \\
\text { momentos, não é?!" (13_IPA) }\end{array}$ \\
\hline & $\begin{array}{l}\text { C4.2(PCKD) - Importância } \\
\text { das ideias dos alunos }\end{array}$ & "[...] Eles percebem que eu preciso das respostas deles durante a aula". (14_IPA) \\
\hline & $\begin{array}{l}\text { C4.3(PCKD) - Necessidade da } \\
\text { interação entre os alunos e o } \\
\text { professor }\end{array}$ & $\begin{array}{l}\text { "[...] na verdade deveria ser assim sempre, né, não só nesse momento que a gente vai lá e } \\
\text { faz. uma intervenção diferente, deveria ser assim sempre". (14_IPA) }\end{array}$ \\
\hline
\end{tabular}




\begin{tabular}{|c|c|c|}
\hline \multirow{4}{*}{ 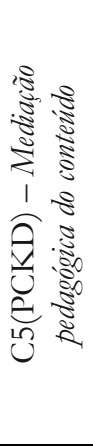 } & $\begin{array}{l}\text { C5.1(PCKD) - Explanação e } \\
\text { problematização do conteúdo }\end{array}$ & $\begin{array}{l}\text { [...] Se eu tivesse chegado lá e falado assim, a concentração em título é isso, a concentração } \\
\text { em quantidade de matéria é isso... eles iam no máximo usar a fórmula, fazer uns cálculos, } \\
\text { mas não iam conseguir associar nada...”. (15_MPC) }\end{array}$ \\
\hline & $\begin{array}{l}\text { C5.2(PCKD) - Proble } \\
\text { sobre um tema do cot }\end{array}$ & $\begin{array}{l}\text { "[...] uma problemática relacionada a um tema instiga mais eles, eu acho que eles se } \\
\text { envolvem mais porque está mais relacionada ao dia a dia". 16_MPC) }\end{array}$ \\
\hline & $\begin{array}{l}\text { C5.3(PCKD }) \text { - Atividades } \\
\text { contextualizadas }\end{array}$ & $\begin{array}{l}\text { "Olha, eu acho que em relação a essa aproximação deles com o cotidiano, utilizar uma } \\
\text { temática, trabalhar os rótulos, faz toda diferença...". (17_MPC) }\end{array}$ \\
\hline & $\begin{array}{l}\text { C5.4(PCKD) - Aplicação do } \\
\text { conhecimento aprendido em } \\
\text { situações do dia a dia }\end{array}$ & $\begin{array}{l}\text { "Ta ficar aquela decoreba, né: "ah eu sei que têm as três soluções, uma é assim, a outra é } \\
\text { assim e a outra é assado, mas eu não sei onde isso está presente". Mas assim, até quando } \\
\text { eles forem preparar um suco eles vão saber que estão preparando uma solução [...]"; } \\
\text { (18_MPC) }\end{array}$ \\
\hline
\end{tabular}

Fonte: adaptado de Arrigo (2021, p. 161-162)

Podemos verificar, no Quadro 2, uma síntese dos fatores responsáveis pela ampliação do PCK de Mary Jane, ao qual assim nos referimos por termos percebido que o PCK identificado na análise das orientações reaparece na análise das discussões pós, acompanhado de reflexões embasadas nas situações de ensino vivenciadas. É perceptível que ela faz considerações sobre as ações dos alunos quando reflete sobre a aprendizagem e a participação e acerca da sua própria ação, tecendo considerações sobre o planejamento, a interação professor-aluno e a mediação pedagógica do conteúdo.

Em nosso entendimento, tais reflexões validam o seu planejamento e representam a construção de conhecimentos acerca do ensino e aprendizagem, dos alunos, do conteúdo, das estratégias de ensino, do contexto, da gestão do conteúdo, da turma e das atividades. Logo, constatamos que todos esses elementos foram construídos pela ampliação dos conhecimentos da base de conhecimentos (SHULMAN, 1987) mobilizados durante o planejamento, o conteúdo, o contexto e o conhecimento pedagógico geral, identificados como base no modelo de Grossman (1990).

Por isso, tomando como base as teorias de Shulman (1987) e Grossman (1990), interpretamos que, durante as orientações, o desenvolvimento do PCK da licencianda ocorreu pela integração dos conhecimentos de base (contexto, conteúdo e pedagógico geral), que foram novamente identificados na análise das discussões pós, aproximando-nos do modelo integrativo de Gess-Newsome (1999). Porém, como esse PCK novamente identificado veio acompanhado de uma análise reflexiva dos resultados da sua prática, defendemos que o desenvolvimento do PCK de Mary Jane, neste caso, ocorreu de forma intermediária entre o modelo integrativo e o transformativo de Gess-Newsome (1999), pois, quando ela retoma o PCK mobilizado nas orientações, verificamos indícios do modelo integrativo, em que os conhecimentos de base não se transformam.

No entanto, quando ela avalia, reflete e constrói novos conhecimentos acerca da docência por meio da contrastação entre o que planejou e o que aconteceu em sala de aula, verificamos indícios do modelo transformativo, indicando que ela construiu um PCK novo, que não voltará a ser como o inicial, o que indica também a transformação dos seus conhecimentos de base, que também não voltarão a ser como os iniciais, uma vez que foram validados pelos resultados da sua ação docente.

\section{CONSIDERAÇÕES FINAIS}

Diante do objetivo de pesquisa - identificar e caracterizar os conhecimentos desenvolvidos pela licencianda sob a perspectiva do PCK ao planejar e implementar atividades de ensino no Estágio de Regência -, tecemos algumas considerações.

No planejamento da AE, verificamos que seu PCK se mobilizou à medida que ela refletiu e planejou a situação-problema, os objetivos, as etapas do experimento e as questões pós-laboratório, e validou tal planejamento com base nas reflexões iniciais acerca do conteúdo e dos seus propósitos de ensino, oriundas da fase de compreensão. Já no planejamento da SD, constatamos que o PCK da licencianda se mobilizou a partir da relação entre o conhecimento do conteúdo, as características da abordagem dos $3 \mathrm{MP}$ e as experiências vivenciadas em sala de aula na realização do experimento que evidenciaram a mobilização de outros conhecimentos da base, como o pedagógico geral e o de contexto, mais evidentes nessa etapa da análise. 
Assim, após as aulas serem ministradas, percebemos que ocorreu o desenvolvimento e a ampliação do PCK da licencianda por meio de um processo reflexivo, que implicou a validação da sua própria prática, levando à construção de novos conhecimentos acerca do ensino e aprendizagem, dos alunos, do conteúdo, das estratégias de ensino, do contexto, da gestão do conteúdo, da turma e das atividades. Neste caso, inferimos que nesse processo de validação ocorreu a legitimação da prática da licencianda, o que implica, portanto, a ampliação do seu PCK e o aprimoramento dos seus conhecimentos de base, que passam a integrar a sua base de conhecimentos para serem mobilizados em situações de ensino futuras, contribuindo, assim, para o seu desenvolvimento profissional docente.

Logo, inferimos que o desenvolvimento do PCK de Mary Jane, neste caso, ocorreu de forma intermediária entre o modelo integrativo e o transformativo de Gess-Newsome (1999), pois, quando ela retoma o PCK mobilizado no planejamento, verificamos indícios do modelo integrativo, em que os conhecimentos de base não se transformam. Por outro lado, quando ela avalia e reflete sobre os resultados da sua prática, verificamos indícios do modelo transformativo, indicando que ela construiu um PCK novo, que não voltará a ser como o inicial, o que indica também a transformação dos seus conhecimentos de base, que também não voltarão a ser como os iniciais, uma vez que foram validados pelos resultados da sua ação docente.

Vale ressaltar também que a estrutura organizacional da disciplina de Estágio de Regência, a interação com a professora-formadora, os métodos de ensino empregados, a turma em que foram realizadas as atividades, tudo isso contribuiu significativamente para a profissionalização de Mary Jane no sentido do desenvolvimento e da ampliação do seu PCK, uma vez que permitiu que ela mobilizasse seus conhecimentos de base e os avaliasse após vivenciar as situações de ensino com base nos resultados tanto das suas ações quanto das ações dos alunos. Portanto, reiteramos os apontamentos feitos no início deste trabalho a respeito do Estágio Supervisionado, como um rico espaço de construção de conhecimentos para a docência.

\section{REFERÊNCIAS}

ABELL, Sandra K. Twenty years later: does pedagogical content knowledge remain a useful idea? International Journal of Science Education, London, v. 30, n. 10, p. 1405-1416, 2008. Disponível em: https://doi.org/10.1080/09500690802187041. Acesso em: 21 maio. 2020.

ARRIGO, Viviane. O conhecimento pedagógico do conteúdo de uma licencianda em química: implicações para o desenvolvimento profissional docente. 2021. 162 f. Tese (Doutorado em Ensino de Ciências e Educação Matemática). Londrina: Universidade Estadual de Londrina, 2021.

BRASIL. Resolução CNE/CP n. 02/2015, de $1^{\circ}$ de julho de 2015. Define as Diretrizes Curriculares Nacionais para a formação inicial em nível superior (cursos de licenciatura, cursos de formação pedagógica para graduados e cursos de segunda licenciatura) e para a formação continuada. Diário Oficial da União, Brasília, DF, 02 de julho de 2015. Seção 1, n. 124, p. 8-12.

BROIETTI, Fabiele C. D.; STANZANI, Enio L. Os estágios e a formação inicial de professores: experiências e reflexões no curso de licenciatura em química da UEL. Química Nova na Escola, São Paulo, v. 38, n. 3, p. 306-317, 2016. Disponível em: http://dx.doi.org/10.21577/0104-8899.20160042. Acesso em: 21 maio. 2020.

CARLSEN, William S. Domains of teacher knowledge. In: GESS-NEWSOME, Julie; LEDERMAN, Norman G. (Orgs.). Examining pedagogical content knowledge: the construct and its implications for science teaching. Dordrecht: Kluwer Academic Publishres, 1999. p. 21-50.

CARVALHO, Anna Maria Pessoa de.; GIL-PÉREZ, Daniel. Formação de professores de Ciências: tendências e inovações. 10 ed. São Paulo: Cortez, 2011. 
DELIZOICOV, Demétrio; ANGOTTI, José André; PERNAMBUCO, Marta Maria. Ensino de ciências: fundamentos e métodos. 4 ed. São Paulo: Cortez, 2011.

DINIZ-PEREIRA, Júlio E. Desenvolvimento profissional docente: um conceito em disputa. In: IMBERNÓN, Francisco; SHIGUNOV NETO, Alexandre; FORTUNATO, Ivan (Orgs.). Formação permanente de professores: experiências iberoamericanas. São Paulo: Edições Hipótese, 2019, p. 65-74.

FERNANDEZ, Carmen. Revisitando a base de conhecimentos e o conhecimento pedagógico do conteúdo (PCK) de professores de ciências. Revista Ensaio, Belo Horizonte, v. 17, n. 2, p. 500-528, 2015.

Disponível em: http://dx.doi.org/10.1590/1983-21172015170211. Acesso em: 21 maio. 2020.

GARCÍA, Carlos M. Desenvolvimento profissional docente: passado e futuro. Sisiffo: Revista de Ciências da Educação, Lisboa, n. 8, p. 7-22, 2009.

Disponível em:

http://www.unitau.br/files/arquivos/category_1/MARCELO__Desenvolvimento_Profissional_Doc ente_passado_e_futuro_1386180263.pdf. Acesso em: 09 abr. 2021.

GESS-NEWSOME, Julie. Pedagogical Content knowledge: an introduction and orientation. In: GESSNEWSOME, Julie; LEDERMAN, Norman G. (Eds.). Examining pedagogical content knowledge. Dordrecht: Kluwer Academic Publishers, 1999. p. 3-17.

GOES, Luciane F. Conhecimento pedagógico do conteúdo: estado da arte no campo da educação e no ensino de química. 2014. 155 f. Dissertação (Mestrado em Ensino de Ciências). São Paulo: Universidade de São Paulo, 2014.

GROSSMAN, Pamela L. The making of a teacher: teacher knowledge and teacher education. New York: Teachers College Press, 1990.

HUME, Anne; COOPER, Rebecca; BOROWSKI, Andreas (Eds.). Repositioning Pedagogical Content Knowledge in Teachers' Knowledge for Teaching Science. Springer Nature Singapore, 2019.

MAGNUSSON, Shirley; KRAJICK, Joseph; BORKO, Hilda. Nature, sources, and development of pedagogical content knowledge for science teaching. In: GESS-NEWSOME, Julie; LEDERMAN, Norman G. (Orgs.). Examining pedagogical content knowledge: the construct and its implications for science education. Dordrecht: Kluwer Academic Publishers, 1999. p. 95-132.

MORAES, Roque; GALIAZZI, Maria C. Análise textual discursiva. 2. ed. Ijuí: Editora Unijuí, 2011. 224p.

MORINE-DERSHIMER, Greta; KENT, Todd. The complex nature and sources of teachers' pedagogical knowledge. In: GESS-NEWSOME, Julie; LEDERMAN, Norman G. (Orgs.). Examining pedagogical content knowledge: the construct and its implications for science education. Dordrecht: Kluwer Academic Publishers, 1999, p. 21-50.

PARK, Soonhye; OLIVER, Steve. Revisiting the conceptualization of pedagogical content knowledge (PCK): PCK as a conceptual tool to understand teachers as professionals. Research in Science Education, New York, v. 38, p. 261-284, 2008. Disponível em: http://dx.doi.org/10.1007/s11165-007-9049-6. Acesso em: 21 maio. 2020. 
ROLLNICK, Marissa et al. The place of subject matter knowledge in pedagogical content knowledge: a case study of South African teachers teaching the amount of substance and chemical equilibrium. International Journal of Science Education, London, v. 30, n. 10, p. 1365-1387, 2008.

SCHÖN, Donald A. Educando o profissional reflexivo: um novo design para o ensino e a aprendizagem. Tradução de Roberto Cataldo Costa. Porto Alegre: Artmed, 2000.

SCHÖN, Donald A. Formar professores como profissionais reflexivos. In: NÓVOA, António. (Coord.). Os professores e a sua formação. Lisboa: Dom Quixote, 1992. p. 79-91.

SHULMAN, Lee S. Knowledge and teaching: foundations of the new reform. Harvard Educational Review, Harvard, v. 57, n. 1, p. 1-21, 1987. Disponível em:

https://doi.org/10.17763/haer.57.1.j463w79r56455411. Acesso em: 21 maio. 2020.

SHULMAN, Lee S. Those who understand: knowledge growth in teaching. Educational Researcher, Thousand Oaks, California, v. 15, n. 2, p. 4-14, 1986. Disponível em:

https://doi.org/10.3102/0013189X015002004. Acesso em: 21 maio. 2020.

SILVA, Rejane M. G.; SCHNETZLER, Roseli P. Concepções e ações de formadores de professores de química sobre o estágio supervisionado: propostas brasileiras e portuguesas. Química Nova, São Paulo: PubliSBQ, v. 31, n. 8, p. 2174-2183, 2008.

Disponível em: http://static.sites.sbq.org.br/quimicanova.sbq.org.br/pdf/Vol31No8_2174_44ED07185.pdf. Acesso em: 21 maio. 2020.

\section{CONTRIBUIÇÃO DAS/DOS AUTORES/AS}

Autora 1 - Coordenadora do projeto, idealização do estudo, coleta e análise de dados, escrita, revisão e edição do manuscrito. Autor 2 - Orientação do estudo, análise de dados e revisão do manuscrito.

Autora 3 - Revisão e edição do manuscrito.

Autora 4 - Revisão e edição do manuscrito.

\section{DECLARAÇÃO DE CONFLITO DE INTERESSE}

Os autores declaram que não há conflito de interesse com o presente artigo.

Submetido: $10 / 05 / 2021$

Aprovado: $30 / 11 / 2021$ 